\title{
Transcriptional silencing of Ty1 elements in the RDN1 locus of yeast
}

\author{
Mary Bryk, ${ }^{1}$ Mukti Banerjee, ${ }^{1}$ Michael Murphy, ${ }^{1}$ Karen E. Knudsen, ${ }^{2}$ David J. Garfinkel, ${ }^{2}$ \\ and $M$. Joan Curcio ${ }^{1,3}$

\begin{abstract}
${ }^{1}$ Molecular Genetics Program, Wadsworth Center and School of Public Health, State University of New York at Albany, Albany, New York 12201-2002; ${ }^{2}$ Gene Regulation and Chromosome Biology Laboratory, National Cancer InstituteFrederick Cancer Research and Development Center (NCI-FCRDC), ABL-Basic Research Program,
\end{abstract} \\ Frederick, Maryland 21702-1201 USA
}

We demonstrate that in Saccharomyces cerevisiae, the tandem array of ribosomal RNA genes (RDN1) is a target for integration of the Ty1 retrotransposon that results in silencing of Ty1 transcription and transposition. Ty1 elements transpose into random rDNA repeat units and are mitotically stable. In addition, we have found that mutation of several putative modifiers of $R D N 1$ chromatin structure abolishes silencing of Ty1 elements in the rDNA array. Disruption of SIR2, which elevates recombination in RDN1, or TOP1, which increases psoralen accessibility in rDNA, or HTA1-HTB1, which reduces histone H2A-H2B levels and causes localized chromatin perturbations, abolishes transcriptional silencing of Ty1 elements in RDN1. Furthermore, deletion of the gene for the ubiquitin conjugating enzyme Ubc2p, which ubiquitinates histones in vitro, derepresses not only Tyl transcription but also mitotic recombination in RDN1. On the basis of these results, we propose that a specialized chromatin structure exists in $R D N 1$ that silences transcription of the Ty1 retrotransposon.

[Key Words: Ty1; rDNA; chromatin; transcriptional silencing; UBC2; histones $\mathrm{H} 2 \mathrm{~A}-\mathrm{H} 2 \mathrm{~B}$ ]

Received October 4,1996; revised version accepted December 2, 1996.

The expression of retroviral proviruses and related families of retrotransposons may be affected by their position of integration (Feinstein et al. 1982; Conklin and Groudine 1986; Akroyd et al. 1987; Curcio and Garfinkel 1991a). Typically, the effect observed is silencing of the expression of certain integrated proviruses or retrotransposons. This phenomenon is poorly understood but it is reminiscent of the position-dependent silencing of transcription units in heterochromatic regions of yeast (Laurenson and Rine 1992), Drosophila (Weiler and Wakimoto 1995), and mouse (Bedell et al. 1996) genomes, a process known as position effect. In Saccharomyces cerevisiae, there are at least two regions of repeated DNA sequences where positional silencing occurs, the homothallic mating loci $(H M)$ and telomeres. Several transacting modifiers of position effect have been identified, including products of the SIR2 (MAR1), SIR3 (MAR2), SIR4, RAP1, and $A B F 1$ genes, histones $\mathrm{H} 3$ and $\mathrm{H} 4$, and the origin recognition complex (for review, see Rivier and Pillus 1994; Shore 1994; Dillin and Rine 1995). The essential role of histones in silencing (Thompson et al. 1994) and the inaccessibility of silenced domains to DNA-modifying enzymes (Park and Szostak 1990; Gottschling 1992; Singh and Klar 1992; Wright et al. 1992; Loo and Rine 1994) have led to the hypothesis that

${ }^{3}$ Corresponding author.

E-MAIL curcio@wadsworth.ph.albany.edu; FAX (518) 474-3181. a heterochromatin-like conformation in these domains is responsible for transcriptional silencing.

The RDN1 locus, which encodes a large tandem array of ribosomal RNA genes, has characteristics of heterochromatin. First, the RDN1 locus consists of tandemly repeated DNA sequences, a situation analogous to that of sequences in heterochromatic domains of higher eukaryotes (Lohe and Hilliker 1995). Second, each copy of the rRNA gene repeat contains DNA sequences that have been implicated in transcriptional silencing at telomeres and the $H M$ loci, including a Raplp-binding site and an autonomously replicating sequence (ARS; Dillin and Rine 1995). Third, recombination is repressed at $R D N 1$, a characteristic of silenced regions of the Drosophila and Schizosaccharomyces pombe genomes (Petes 1980; Szauter 1984; Christman et al. 1988; Thon et al. 1994). Significantly, SIR2, which is required for transcriptional silencing at the $H M$ loci and telomeres, is also required for suppressing recombination in $R D N 1$ (Gottlieb and Esposito 1989). In contrast to the other heterochromatin-like regions in yeast, however, genes in $R D N 1$ are transcribed actively. This includes not only the RNA polymerase (Pol) I-transcribed 35S rRNA gene and Pol III-transcribed 5S rRNA gene present in each rDNA repeat, but also Pol II-transcribed genes URA3 and LEU2 introduced into RDN1 (Szostak and Wu 1980; Gottlieb and Esposito 1989).

This study was undertaken to determine whether the 
chromosomal position of a retroelement insertion can influence its expression. The Tyl element of yeast is a long terminal repeat (LTR)-containing retrotransposon present in $-25-35$ copies per haploid genome. A characteristic of Tyl biology that facilitates the identification of transposition events whose expression is affected by adjacent chromatin is that the amount of RNA produced from an individual Tyl element determines its rate of transposition. The total level of Tyl proteins, rather than RNA, limits transposition; consequently, competition between Tyl RNA for association with the Tyl proteins that mediate cDNA synthesis determines the level of transposition of each element (for review, see Farabaugh 1995). Furthermore, the functional state of proteins encoded by a particular Tyl element does not affect its rate of transposition, as Tyl proteins act efficiently in trans. In contrast, the transcript of a Tyl element is cisacting in its role as template for reverse transcription; therefore, changes in the transcription of an individual element that do not affect total Tyl RNA levels can affect the transposition of that individual element (Curcio and Garfinkel 1994). Individual Tyl elements have been demonstrated to express varied levels of RNA and differ as much as 50 -fold in their rate of transposition (Curcio and Garfinkel 1991b).

Although Tyl elements have been shown to transpose into numerous selectable target loci, studies of unselected transposition events have shown that integration is not random. Like that of retroviruses, Tyl integration is not sequence specific (Natsoulis et al. 1989; Ji et al. 19931, but is influenced by the structural or functional state of chromatin (for review, see Curcio and Morse 1996). Tyl elements frequently integrate into the vicinity of tRNA genes (Ji et al. 1993), and recent work by Devine and Boeke (1996) has established that the presence of an actively transcribed Pol III gene, including tRNA, 5S rRNA, or snRNA genes, stimulates Tyl integration into target plasmids. Tyl elements have also been found associated with 5S rRNA genes in the RDN1 locus (Piper et al. 1984; Vincent and Petes 1986); in general, however, Tyl elements are underrepresented or absent in the rDNA array (Oyen and Gabrielsen 1983; Rustchenko and Sherman 1994). Interestingly, the 5S rRNA gene located in the rDNA array is also a poor target for the Ty3 retrotransposon in comparison to a plasmid-borne 5S rRNA gene (Chalker and Sandmeyer 1992).

To determine whether the position of integration of a Ty1 retrotransposon could influence its expression, we induced transposition of a Tyl element and screened for strains that have unselected de novo Tyl insertions marked with the his $3 A I$ retrotransposition indicator gene (Curcio and Garfinkel 1991b). Several Tylhis3AI insertions, which had very low levels of transposition and transcription, were identified. We show that most of the inactive elements integrated into different rDNA repeats on chromosome XII, suggesting that transcriptional silencing was a consequence of their position of integration.

To understand the mechanism of Tylhis $3 A I$ element silencing in $R D N 1$, we examined several genes whose products potentially alter chromatin structure and the biology of $R D N 1$. One potential modifier of chromatin assembly that was analyzed was $U B C 2(R A D 6)$, a DNA repair gene that encodes an E2 ubiquitin-conjugating enzyme that participates in several diverse cellular processes. A role for $U B C 2(R A D 6)$ as a modifier of localized chromatin domains is suggested by the observation that Tyl integration specificity into target genes is altered significantly in $u b c 2 \Delta$ mutants (Kang et al. 1992; Liebman and Newnam 1993). Moreover, a recent report suggests that ubiquitinization of histones or chromatin-associated proteins provides a means to remodel chromatin in yeast (Moazed and Johnson 1996). To establish a direct connection between chromatin structure and regulation of Tyl elements in $R D N 1$, we have also investigated the effect of deleting the HTA1-HTB1 locus, one of two loci that encodes the histones $\mathrm{H} 2 \mathrm{~A}$ and $\mathrm{H} 2 \mathrm{~B}$. The $\mathrm{H} 2 \mathrm{~A}-\mathrm{H} 2 \mathrm{~B}$ dimer is a component of the nucleosome core whose depletion causes nucleosome instability, local perturbations in chromatin structure, altered positioning of nucleosomes at specific promoters, altered transcription of specific genes in yeast (Han et al. 1987; Clark-Adams et al. 1988; Han and Grunstein 1988; Norris et al. 1988; Hirschhorn et al. 1992), and suppression of position-effect variegation in Drosophila (Moore et al. 1983).

Here we identify $U B C 2$, SIR2, TOP1, and HTA1HTB1 as modifiers of Tyl element silencing in the rDNA array. Our findings reveal an unprecedented role for $U B C 2$ in transcriptional silencing and repression of recombination in $R D N 1$. The participation of the histone dimer $\mathrm{H} 2 \mathrm{~A}-\mathrm{H} 2 \mathrm{~B}$ and topoisomerase I in transcriptional silencing indicates that a specialized chromatin structure in RDN1 regulates expression of Ty1 elements. The requirement for the chromatin modifier encoded by SIR2 suggests that the mechanism of silencing in RDN1 is related to the SIR2-dependent suppression of rDNA repeat recombination and to position effect at telomeres and the HM loci. We discuss models whereby these modifiers facilitate the formation of a chromatin structure in RDN1 that represses Tyl transcription and recombination between rDNA repeats.

\section{Results}

De novo Ty1his3AI integrants differ in transpositional activity

Colonies that undergo transposition-induction by expression of plasmid pGTyl-H3mhis3AI sustain an average of 1.7 marked transposition events per genome, and most of the insertions retain the retrotransposition indicator gene his $3 A I$ because of inefficient splicing of the artificial intron (AI; Curcio and Garfinkel 1991b). The his $3 A I$ retrotransposition indicator gene, which consists of an $\mathrm{AI}$ cloned in antisense orientation into the coding sequences of the HIS3 gene, confers a $\mathrm{His}^{-}$phenotype (Fig. 1). The marker gene can be converted into a functional HIS3 allele in the process of Tyl retrotransposi- 


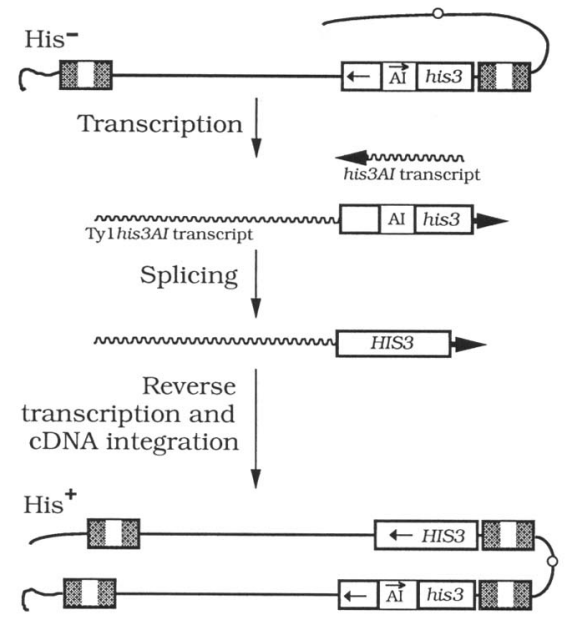

Figure 1. Transposition of a genomic his $3 A I$-marked Tyl element. A chromosomal Tyl element is marked with a HIS 3 gene (open rectangle) in the opposite transcriptional orientation to Ty1. Coding sequences of the HIS 3 gene are interrupted by an artificial intron (AI) in the antisense orientation relative to the HIS 3 coding sequence. The $\mathrm{AI}$ is not spliceable from transcripts that initiate from the HIS3 promoter; however, it is in the correct orientation to be spliced from Tyl transcripts. When a spliced transcript from the Ty1his $3 A I$ element is used as template for reverse transcription and integration, the newly transposed element will contain a functional copy of HIS 3 created by precise removal of the AI, rendering the cell phenotypically $\mathrm{His}^{+}$. The TylHIS 3 transposition event is shown on the same chromosome for simplicity. (Tripartite stippled and open boxes) LTRs; (bold lines) chromosomes; (open circles) centromeres; (wavy lines) RNA transcripts.

tion, and in doing so, renders the cell phenotypically His $^{+}$. The rate of transposition of Tylhis $3 A I$ elements is directly proportional to the rate of formation of histidine prototrophs in his $3 \Delta 200$ strains (Curcio and Garfinkel 1991b).

To investigate the role of transcriptional silencing in the variability of genomic Tyl element expression, we screened transposition-induced colonies by Southern hybridization for yeast strains that contained a single de novo Tylhis $3 A I$ transposition event. The transposition activity of Tylhis $3 A I$ elements was determined initially in a test for $\mathrm{His}^{+}$prototroph formation at $20^{\circ} \mathrm{C}$ in a small patch of cells. Active Tylhis $3 A I$ elements, which have rates of $\mathrm{His}^{+}$prototroph formation of $10^{-6}$ to $10^{-7}$ per generation (Curcio and Garfinkel 1991b, 1992), typically represent $\sim 75 \%$ of the de novo transposition events after induction of pGTy1-H3mhis $3 A I$ expression. However, seven Tylhis $3 A I$-containing strains were found that had a relatively low frequency of $\mathrm{His}^{+}$prototrophy. The rate of $\mathrm{His}^{+}$prototroph formation was determined for each of the seven strains as well as strains JC242 and JC273, which harbor active Ty1his $3 A I$ elements (Table 1). The seven transpositionally inactive strains had rates of $\mathrm{His}^{+}$ prototroph formation ranging from $<1.2 \times 10^{-9}$ to $2.5 \times 10^{-8}$. In contrast, active elements Tylhis $3 A I-242$ and Tylhis $3 A I-273$ produced $-1.5 \times 10^{-7} \mathrm{His}^{+}$proto- trophs per generation. The data show that the transposition rates of inactive Tylhis $3 A I$ elements can be at least 100 -fold lower than that of typical active elements (Table 1).

\section{Mapping inactive Ty1his3AI elements to RDN1}

To determine whether the seven genomic Tylhis $3 A I$ elements exhibiting low levels of transposition share a common location in the yeast genome, chromosomes from strains with inactive Tylhis $3 A I$ elements (JC234, JC236, JC272, JC815, JC816, JC820, and JC821), and active Ty1his3AI elements (JC242 and JC273) were separated by contour-clamped homogenous electric field (CHEF) gel electrophoresis, and the Tylhis $3 A I$ elements were mapped by hybridization to a HIS3 probe (Fig. 2A). Five inactive Tylhis $3 A I$ elements were located on chromosome XII, the identity of which was confirmed by rehybridizing the CHEF blot with a chromosome XIIspecific probe (data not shown). In contrast, the other two inactive Tylhis $3 A I$ elements and the two active elements were located on four different chromosomes. Tylhis $3 A I-815$ and Tylhis $3 A I-821$ mapped to chromosomes $\mathrm{X}$ and XVI, respectively. The transpositionally active element Tylhis $3 A I-273$ was located on chromosome II (data not shown) and Tylhis $3 A I-242$ was located on chromosome XII, demonstrating that location on this chromosome did not in itself result in low levels of transposition.

Southern analysis revealed that the inactive Ty1his3AI elements that mapped to chromosome XII were on a common-sized Sfil fragment (data not shown). Therefore, a DNA fragment containing the junction between Tyl his $3 A I$ and genomic sequences downstream of the $3^{\prime}$ LTR was isolated from each strain by integration and eviction of pGEM-HIS3, a plasmid containing the HIS3 gene on an Escherichia coli vector. The sequence of the Tylhis $3 A I$ insertion junctions was determined (Fig. 2B). The five inactive Tylhis3AI insertions on chromosome XII had all integrated into an rDNA repeat (Fig.

Table 1. Transposition of genomic Ty1his3AI elements

\begin{tabular}{|c|c|c|c|c|}
\hline \multirow[b]{2}{*}{ Strain } & \multirow{2}{*}{$\begin{array}{l}\text { Location of } \\
\text { Tylhis } 3 A I \\
\text { element }\end{array}$} & \multicolumn{2}{|c|}{ Transposition rate ${ }^{\mathbf{a}}$} & \multirow{2}{*}{$\begin{array}{l}\text { Ratio of rates } \\
\text { (ubc2 } 2 \Delta / U B C 2)\end{array}$} \\
\hline & & $U B C 2$ & $u b c 2 \Delta$ & \\
\hline $\mathrm{JC} 234$ & $R D N 1$ & $3.4 \times 10^{-9}$ & $3.7 \times 10^{-8}$ & 11 \\
\hline $\mathrm{JC} 236$ & $R D N 1$ & $1.1 \times 10^{-8}$ & $1.9 \times 10^{-7}$ & 17 \\
\hline $\mathrm{JC} 272$ & RDN1 & $<1.2 \times 10^{-9}$ & $8.7 \times 10^{-8}$ & $>73$ \\
\hline $\mathrm{JC} 816$ & RDN1 & $<1.3 \times 10^{-9}$ & $6.6 \times 10^{-8}$ & $>50$ \\
\hline $\mathrm{JC} 820$ & $R D N 1$ & $<1.8 \times 10^{-9}$ & $1.3 \times 10^{-7}$ & $>70$ \\
\hline JC815 & Chr X & $2.5 \times 10^{-8}$ & $<5.9 \times 10^{-9}$ & $<0.2$ \\
\hline $\mathrm{JC} 821$ & Chr XVI & $<1.8 \times 10^{-9}$ & $<1.7 \times 10^{-9}$ & - \\
\hline $\mathrm{JC} 242$ & Chr XII' ${ }^{b}$ & $1.6 \times 10^{-7}$ & $1.4 \times 10^{-7}$ & 0.9 \\
\hline $\mathrm{JC} 273$ & Chr II & $1.5 \times 10^{-7}$ & $1.1 \times 10^{-7}$ & 0.7 \\
\hline
\end{tabular}

${ }^{a}$ The rate of $\mathrm{His}^{+}$prototroph formation per cell per generation, as determined by the maximum likelihood method of Lea and Coulson (1949).

boutside RDN1. 
Bryk et al.

A

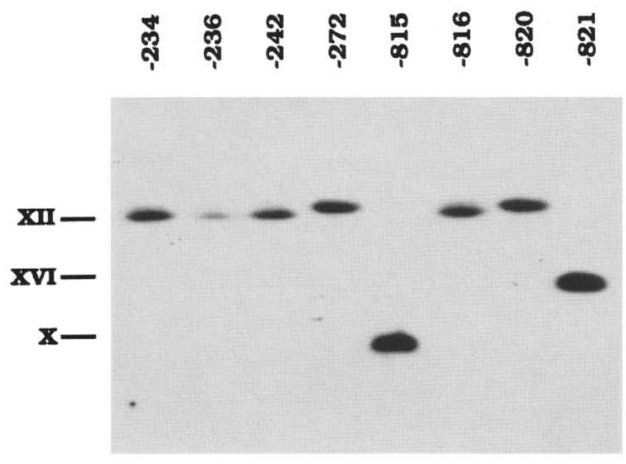

B

-234 acccaattctcaGTTTTGCATTTACGGCACCGGATGCGGGCGATAATGAC

-236 acccaattctcaTTTTTCATATCAAAGGCATGTCCTGTTAACTATAGGAAA

-242 acccaattctcaGCAACCACAGTTGAAATAGCAGAATATTCAGCAAAGCA -272 acccaattctcaATATGACAGGTGAAAAAGCAAAAGCAATAGTGCATTGT -815 acccaattctcaCATAACTAATGCGATCGATCTTAGCACCATATATGATAA -816 acccaattctcaCAAACTTTACTACTATCCTCCCTTCAGTTTCCCTTTTTCT -820 acccaattctcaGTTATACCATGTAGTAAAGGAACTATCAAATAAACGATA

C

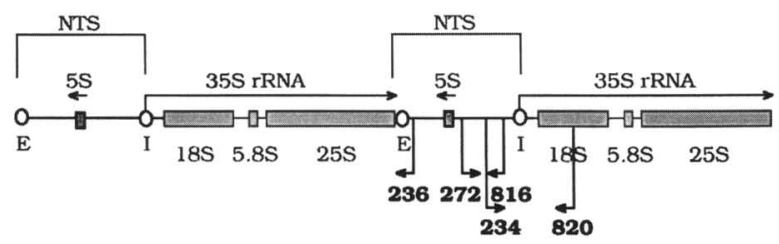

Figure 2. Determination of Tylhis $3 A I$ integration sites. $(A)$ Agarose-embedded DNA was prepared from the strains listed above the lanes, and individual chromosomes were separated by CHEF gel electrophoresis, transferred to a nylon membrane, and hybridized to a HIS 3 riboprobe. Labels 234 through 821 indicate the number of the strain and the Tylhis $3 A I$ insertion. The locations of chromosomes XII, XVI, and X are indicated. $(B) \mathrm{Se}$ quence of Tylhis 3 AI-flanking genomic DNA junctions. Tyl $3^{\prime}$ LTR is in lowercase lettering; genomic sequences downstream of the 3' LTR are in uppercase lettering. Labels, as in $A .(C)$ Schematic representation of two rDNA repeats depicting the locations of five inactive Tyl his $3 A I$ elements. (Hatched boxes) rRNA genes, 35S (18S, 5.8S, and 25S) and 5S. (Bold vertical lines) Position of the Tylhis $3 A I$ insertion. (Small arrows) Direction of transcription. (E) Enhancer of RNA Pol I; (I) Initiator of RNA Pol I; (NTS) nontranscribed spacer. Insertion sites of Tylhis $3 A I$ are as follows: $-272,-234$, and -816 at 120,360 , and 841 bp upstream of the $5 \mathrm{~S}$ rRNA transcription initiation site, respectively; -236 at 701 bp downstream of the 5 SRNA transcription termination site; -820 , in $18 \mathrm{~S}$ rRNA gene, at 844 bp downstream of the $35 \mathrm{~S}$ rRNA initiation site.

$2 C)$. There are $\sim 100-200$ copies of the 9.1-kb rDNA repeat in yeast, which are found in a tandem array in the $R D N 1$ locus. Each repeat contains the transcription unit for the $35 \mathrm{~S}$ precursor to $25 \mathrm{~S}, 18 \mathrm{~S}$, and 5.8S rRNA, transcribed by Pol I. In addition, there is a $2.5-\mathrm{kb}$ nontranscribed spacer (NTS) in each repeat. The NTS consists of promoter elements for the 35S rRNA gene flanking the 120-bp 5S rRNA gene, which is transcribed in the opposite orientation by Pol III. In strains JC234, JC236, JC272, and JC816, Tylhis $3 A I$ insertions were found in the NTS on either side of the $5 \mathrm{~S}$ rRNA gene. The Tylhis $3 A I$ element in strain JC820 was inserted in the 35S rRNA gene (Fig. 2C).

The junction between Tylhis $3 A I$ and adjacent genomic sequences was also isolated from the two strains with transpositionally active Tylhis $3 A I$ elements. The integration site of Tylhis $3 A I-242$ at position 1060533 of chromosome XII was in an open reading frame (ORF) just outside of the $R D N 1$ locus. The inactive element Tylhis $3 A I-815$ at position 354470 of chromosome X was flanked by 70 nucleotides from the middle of a Ty 1 LTR in the same orientation, followed by 150 nucleotides of a Ty2 LTR in the opposite orientation. In summary, although both inactive and active Tyl elements mapped to random locations outside of $R D N 1$, most (five of seven) inactive Tylhis $3 A I$ elements were found in RDN1.

\section{Ty1his3AI elements are located in dispersed rDNA} repeats

The number and location of Tylhis $3 A I$ elements in $R D N 1$ were determined by CHEF gel analysis of chromosomal DNA digested with BamHI. No BamHI sites are present in $R D N 1$, therefore, digestion with BamHI leaves the 1- to 2-Mb RDN1 locus intact. However, a single BamHI site is present in Tylhis $3 A I$; therefore, insertion into RDN1 will result in BamHI-generated subfragments of $R D N 1$.

Undigested and BamHI-digested chromosomal DNA from strains containing Tylhis $3 A I$ insertions was separated on CHEF gels and hybridized to an $18 \mathrm{~S}$ rRNA probe and a HIS3 probe (Fig. 3A,B). The sizes of the BamHI fragments hybridizing to the $18 \mathrm{~S}$ rRNA probe were determined by comparison to size standards. The length of $R D N 1$ is highly variable, ranging from $\sim 1000$ to $1900 \mathrm{~kb}$ among the insertion-containing strains (Fig. 3). These lengths correspond to $110-210$ copies of the $9.1-\mathrm{kb}$ rDNA repeat, respectively.

In strains JC242 and JC273, a single large BamHI fragment was detected with the 18S rRNA probe, consistent with there being no Tylhis3AI element in RDN1 in these strains. In contrast, two BamHI fragments hybridized to the 18S rRNA probe in DNA from strains JC234, JC236, and JC272, one of which also hybridized to HIS3 (Fig. 3A,B). BamHI digestion of chromosomal DNA from strains JC816 and JC820 generated three fragments that hybridized to the $18 \mathrm{~S}$ rRNA probe (Fig. 3A), but only a $1025 \mathrm{~kb}$ band in JC816 DNA and a 900-kb band in JC820 DNA hybridized to HIS3 (Fig. 3B). CHEF analysis of single-colony isolates of JC816 and JC820 revealed that both strains contain mixed populations of cells with at least two different sized RDN1 loci that have consistently a single $B a m H I$ site (data not shown). The presence of only one $B a m H I$ fragment in DNA from strains JC234, JC236, JC272, JC816, and JC820 that hybridized 
A

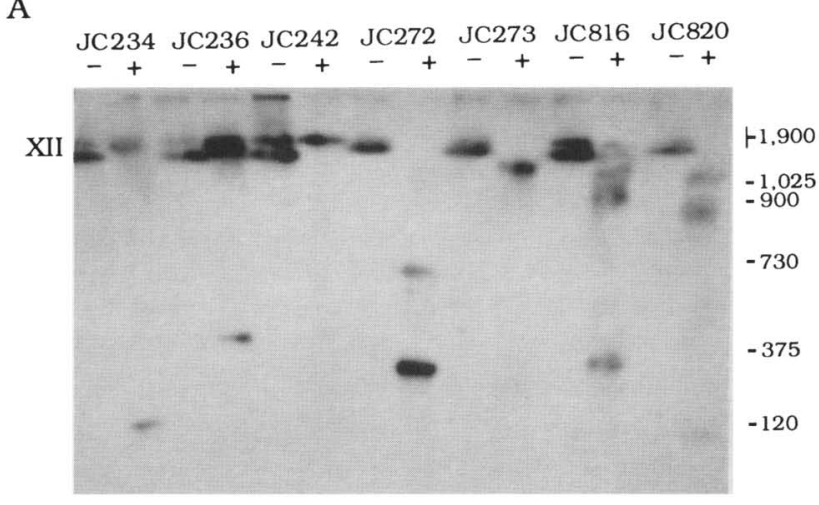

B

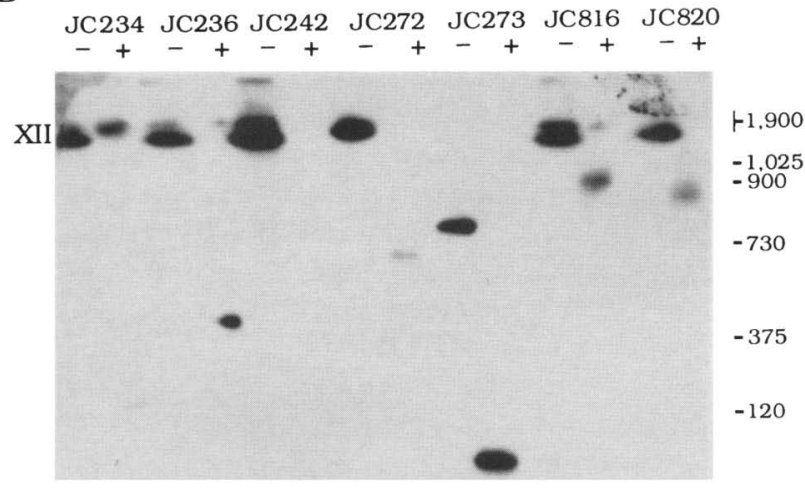

C

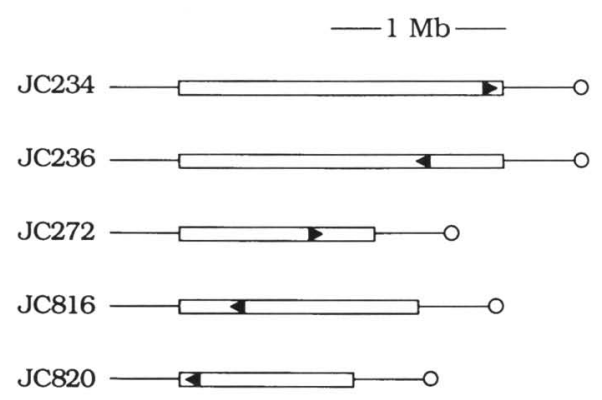

Figure 3. Location of Tylhis $3 A I$ elements in the rDNA array. (A) Chromosomal DNA from strains containing Tylhis $3 A I$ elements was incubated in the absence $(-)$ or presence $(+)$ of BamHI and separated by CHEF gel electrophoresis. The DNA was transferred to a nylon membrane and hybridized to a ${ }^{32} \mathrm{P}$ labeled 18S rRNA riboprobe. The location of chromosome XII and fragment sizes $(\mathrm{kb})$ are indicated. Undigested chromosome XII often bands as a doublet because of its large size. $(B)$ The Southern blot from $A$ was hybridized with a HIS3 DNA probe. Labels, as in $A .\{C\}$ Schematic representation of $R D N 1$ depicting the location and orientation of Tylhis $3 A I$ insertions. The data from $A$ and $B$ were used to determined the relative location and orientation of each Tylhis $3 A I$ element in RDN1. The BamHI fragment that hybridized to HIS 3 contains the upstream portion of the Tylhis $3 A I$ element. This information and the orientation of the Tyl element (Fig. 2C) was used to determine the location of the Tyl insertion (solid arrowhead) in RDN1. For strains JC816 and JC820, the smallest BamHI fragment 1370 and 120 $\mathrm{kb}$, respectively) was added to that of the HIS3-hybridizing fragment (1025 and $900 \mathrm{~kb}$, respectively). Only the length of RDN1 (open rectangles) is drawn to scale. (O) Centromere; $(\mathrm{Mb})$ megabase. to both probes indicates that a single Tylhis $3 A I$ element inserted into $R D N 1$. These mapping data, together with the known orientation of the Tylhis $3 A I$ element within an rDNA repeat (see Fig. 2C), were used to determine the position of the marked Tyl element within RDN1, which is shown schematically in Figure 3C. The results suggest that rDNA repeats located throughout RDN1, rather than in a specific location in $R D N 1$, serve as targets for Tyl element insertion.

To determine the frequency of Tyl insertion into the NTS of the rDNA repeats, strains that sustained Tyl transposition events marked with $H I S 3$ or ADE2 were collected after induction of transposition in strain GRF167, and a PCR assay was used to detect Tyl insertions in a $2.5-\mathrm{kb}$ region encompassing the NTS. (Neither the HIS3 nor the ADE2 marker within a Tyl element is silenced when transposition into rDNA occurs; see below.) We found that 12 of $119(10 \%)$ Tyl insertions analyzed had integrated into an NTS. The data demonstrate that the NTS, whose $100-200$ copies represent $~ 2 \%-4 \%$ of the yeast genome, is an efficient target for de novo integration of Tyl.

\section{Ty1his3AI elements in rDNA are regulated by UBC2}

In a screen of major genes within the DNA repair epistasis groups for their effect on Tyl transposition, we noticed that the $U B C 2$ gene had a differential effect on transpositionally inactive versus active Tyl his $3 A I$ insertions. To test whether $U B C 2$ was involved in silencing of Tyl elements in RDN1, UBC2 was deleted from nine strains containing individual Tylhis $3 A I$ elements. When the transposition rate in $u b c 2 \Delta$ mutants was compared to that of isogenic wild-type strains, two distinct classes of elements emerged (Table 1). Tylhis3AI elements located in RDN1 in strains JC234, JC236, JC272, JC816, and JC820 had low rates of $\mathrm{His}^{+}$prototroph formation ranging from $<1.2 \times 10^{-9}$ to $1.1 \times 10^{-8}$ in wildtype strains and increases of 11 -fold to $>70$-fold in isogenic ubc2 $\Delta$ mutants. A second class of elements located outside RDN1 in strains JC242, JC273, JC815, and JC821 showed the same or slightly lower rates of $\mathrm{His}^{+}$prototrophy in $u b c 2 \Delta$ strains relative to the isogenic wild-type strain. This class was comprised of two elements that transposed at relatively high rates and two that transposed at low rates. These data show that the yeast genome contains one class of Tyl elements located in $R D N 1$ that is repressed transpositionally by a UBC2dependent mechanism and another class located at random positions that is not regulated by $U B C 2$.

The finding that only a subset of Ty1his $3 A I$ insertions in yeast cells is regulated by $U B C 2$ suggests that Ty1his $3 A I$ expression is affected at the level of transcription, as the Tylhis $3 A I$ RNA is cis-acting in its role as template for cDNA synthesis. To verify this, relative levels of Tylhis3AI RNA in UBC2 and isogenic ubc2 strains were determined in Northern hybridization analysis (Fig. 4). The five strains that contain Tyl elements in RDN1 whose transposition is repressed by UBC2, JC234, JC236, JC272, JC816, and JC820, had low 


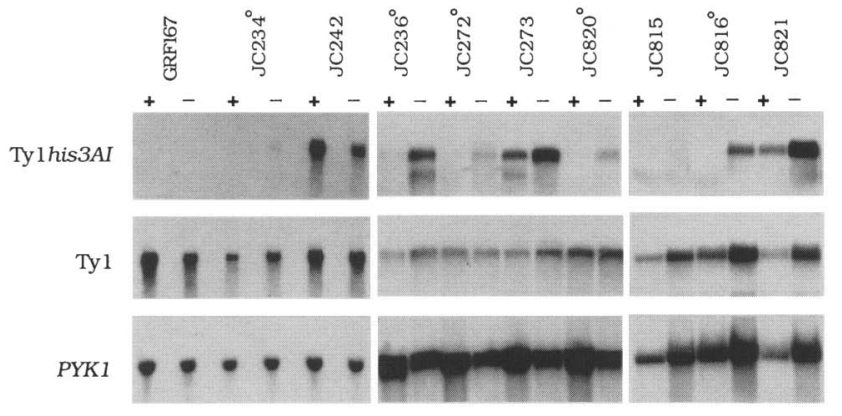

Figure 4. Effect of $u b c 2 \Delta$ mutation on Tylhis $3 A I$ and total Ty1 RNA levels. Total RNA from isogenic $U B C 2(+)$ and $u b c 2 \Delta$ $(-)$ strains containing single Tylhis $3 A I$ insertions was hybridized to a ${ }^{32} \mathrm{P}$-labeled sense-strand HIS3 riboprobe to detect Tylhis3AI RNA (top), an antisense Tyl riboprobe to detect total Ty1 RNA (middle), and an antisense PYK1 riboprobe as a loading control (bottom). GRF167 is the parental strain used to generate derivative strains containing Tylhis $3 A I$ transposition events. Strains with Ty1his $3 A I$ insertions in $R D N 1$ are marked with a superscript 0 . The $u b c 2 \Delta / U B C 2$ ratio of Tyl his $3 A I$ RNA normalized to PYK1 RNA, as determined by scanning densitometry is $\mathrm{JC} 34^{\circ}, 8.1$; JC242, 0.45 ; $\mathrm{JC}^{\circ} 36^{\circ}, 24.3^{\prime} \mathrm{JC}^{\circ} 72^{\circ}, 472.3$; $\mathrm{JC} 273,3.5$; JC820 ${ }^{\circ}, 33.0$; JC815, >0.48; $\mathrm{JC}_{16}{ }^{\circ},>339.2$; JC821, 1.1 .

or undetectable levels of Tylhis $3 A I$ RNA relative to the levels of a control transcript PYK1 RNA. In contrast, Tylhis3AI RNA was increased significantly in isogenic $u b c 2 \Delta$ derivatives. For example, the $u b c 2 \Delta$ mutation increased Tylhis $3 A$ I RNA levels in strain JC 816 by at least 339-fold (Fig. 4). The data demonstrate that UBC2-mediated repression of Tylhis $3 A I$ transposition is attributable to regulation of Tylhis $3 A I$ element RNA levels. On the other hand, the four strains containing Tylhis $3 A I$ elements whose transposition was not regulated by UBC2 (Table 1) also showed no significant change in Tylhis3AI RNA levels as a result of $u b c 2$ deletion (Fig. 4). The transpositionally active Tylhis $3 A I$ elements in strains JC242 and JC273 were well transcribed in both $U B C 2$ and $u b c 2 \Delta$ strains. The Tylhis $3 A I$ element in JC821 was also highly transcribed in both the $U B C 2$ and $u b c 2 \Delta$ strains although it transposes at a very low rate, indicating that it may contain a cis-acting mutation required for formation of TylHIS3 transposition events. The transpositionally inactive Tylhis $3 A I$ element in strain JC815 had no detectable Tylhis3AI RNA in the presence or absence of $U B C 2$. In summary, the data demonstrate that $U B C 2$ is uniquely required for repressing transcription of Tylhis $3 A I$ elements located in RDN1.

Despite derepression of transcriptionally silenced Tyl elements in $u b c 2$ mutants, total Tyl RNA was not increased significantly in any of the $u b c 2 \Delta$ derivatives of Tylhis $3 A I$-harboring strains or the parental strain GRF167 (Fig. 4). This result has been obtained previously in other yeast strains (Picologlou et al. 1990) and can be explained by the presence of low numbers of Tyl elements in RDN1.

In addition to a role in repressing transcription of Tyl elements in $R D N 1$, the product of the $U B C 2$ gene has been shown to participate in $\mathrm{N}$-end rule protein degradation, postreplicative DNA repair, induced mutagenesis, and sporulation (Prakash et al. 1993; Lawrence 1994). To determine whether the $\mathrm{N}$-end rule protein degradation function of $U B C 2$ is linked to repression of Ty1his $3 A I$ elements in RDN1, partial activity alleles of $U B C 2$ were tested for complementation of the hypertransposition defect of $u b c 2 \Delta$ mutants. The plasmidborne $u b c 2$ alleles are completely $\left(u b c 2_{\Delta 1-9} u b c 2-149\right)$ or partially (ubc2-153) defective for $\mathrm{N}$-end rule protein degradation (Madura et al. 1993; Watkins et al. 1993). The results in Table 2 show that the CEN vector alone and the $u b c 2_{\Delta 1-9}$ allele did not complement the derepression of Tylhis $3 A I$ transposition, whereas the full-length $U B C 2, u b c 2-149$, and $u b c 2-153$ alleles repressed transposition of rDNA-Tylhis $3 A I$ elements in ubc2 $2 \Delta \mathrm{mu}$ tants. Hence, transcriptional silencing of Ty1 elements in RDN1 is not correlated with loss of $\mathrm{N}$-end rule protein degradation, but must involve another function of $U B C 2$ that is defective in the $u b c 2_{\Delta 1-9}$ allele. Consistent with these findings, a disruption of UBR1, the recognition component of the $\mathrm{N}$-end rule degradation pathway (Dohmen et al. 1991), also did not affect transposition of Tylhis $3 A I$ elements in or outside of $R D N 1$ (data not shown). The results indicate that $U B C 2$-mediated $\mathrm{N}$-end rule protein degradation is not required for silencing of Tyl elements in RDN1.

\section{SIR2 is a regulator of Ty1his3AI element silencing in RDN1}

The SIR2 gene product is required for the maintenance of a repressed chromatin structure that silences transcription units at the HM loci and telomeres and represses recombination between rDNA repeats. Therefore, if transcriptional silencing of Tylhis $3 A I$ elements in

Table 2. Complementation of ubc $2 \Delta$ strains with partial-activity ubc2 alleles

\begin{tabular}{|c|c|c|}
\hline Strain $+u b c 2$ allele ${ }^{a}$ & $\begin{array}{l}\text { Rate of } \\
\text { Tylhis } 3 A I \\
\text { element } \\
\text { transposition }{ }^{\mathrm{b}}\end{array}$ & $\begin{array}{l}\text { Transposition } \\
\text { rate relative } \\
\text { to } U B C 2\end{array}$ \\
\hline $\mathrm{JC} 236 u b c 2 \Delta+U B C 2$ & $2.8 \times 10^{-8}$ & 1 \\
\hline JC236ubc2 2 + vector & $3.4 \times 10^{-7}$ & 12.1 \\
\hline $\mathrm{JC} 236 u b c 2 \Delta+u b c 2_{\Delta 1-9}$ & $1.5 \times 10^{-7}$ & 5.4 \\
\hline $\mathrm{JC} 236 u b c 2 \Delta+u b c 2-149$ & $3.3 \times 10^{-8}$ & 1.2 \\
\hline $\mathrm{JC} 236 u b c 2 \Delta+u b c 2-153$ & $1.3 \times 10^{-8}$ & 0.5 \\
\hline $\mathrm{JC} 272 u b c 2 \Delta+U B C 2$ & $1.1 \times 10^{-8}$ & 1 \\
\hline JC272ubc2 2 + vector & $1.5 \times 10^{-7}$ & 13.6 \\
\hline $\mathrm{JC} 272 u b c 2 \Delta+u b c 2_{\Delta 1}$ & $1.6 \times 10^{-7}$ & 14.5 \\
\hline JC2 $272 u b c 2 \Delta+u b c 2-149$ & $1.3 \times 10^{-8}$ & 1.2 \\
\hline $\mathrm{JC} 272 u b c 2 \Delta+u b c 2-153$ & $1.1 \times 10^{-8}$ & 1 \\
\hline
\end{tabular}

${ }^{a}$ Contained on the URA3-marked plasmid YCp50.

${ }^{\mathrm{b}} \mathrm{The}$ rate of $\mathrm{His}^{+} \mathrm{Ura}^{+}$prototroph formation per $\mathrm{Ura}^{+}$cell per generation, as determined by the method of Lea and Coulson (1949). 
RDN1 is the result of their location in repressed chromatin, disruption of SIR 2 might be expected to relieve positional silencing of Tyl elements. To investigate this, SIR2 was disrupted in strains JC234 and JC272, which contain Tylhis $3 A I$ elements in RDN1, and in strains IC242 and JC273, which have Tylhis3AI elements outside $R D N 1$ and the rates of transposition of Tylhis $3 A I$ elements were assessed (Table 3). Disruption of SIR2 permits expression of the silent $H M L$ and $H M R$ cassettes, resulting in haploid strains that are phenotypically $\mathbf{a} / \alpha$ (Klar et al. 1979; Shore et al. 1984). This alteration of mating type is significant because Tyl RNA is decreased -20 -fold in a/ $\alpha$ cells compared to a or $\alpha$ cells (Elder et al. 1981). In accord with a/ $\alpha$ control of Tyl expression, the transposition rates of Tylhis $3 \mathrm{AI}$ elements in strains containing a marked Tyl element outside RDN1 were decreased 10-fold (Table 3; JC242 and JC273). In contrast, for strains containing a marked Tyl element in $R D N 1$, the rates of transposition of Tylhis3AI increased 8- and $>129$-fold (Table 3; JC234 and JC272, respectively), despite the repressive effect of the $\mathrm{a} / \alpha$ phenotype. Thus, the results indicate that the product of the SIR 2 gene suppresses transposition of Tyl elements in RDN1.

To differentiate between a direct influence of SIR2 disruption or an indirect influence by a/ $\alpha$ regulation, isogenic MAT a $/ \alpha$ and MATa haploid derivatives of strains JC234, JC242, JC272, and JC273 were constructed (see Materials and Methods). In comparison to a or $\alpha$ haploids, Tylhis $3 A I$ elements outside $R D N 1$ transposed at a reduced level in a/ $\alpha$ haploids, equivalent to that observed in the isogenic sir2::URA3 strains (data not shown). However, strains with marked Tyl elements in $R D N 1$ showed repressed levels of $\mathrm{His}^{+}$prototrophy in a, $\alpha$, and $a / \alpha$ derivatives, in contrast to the elevated formation of $\mathrm{His}^{+}$prototrophs seen in sir2::URA3 strains. In addition, we disrupted SIR3, another silencing gene required for repression of the HM loci and telomeres, in strains containing Tylhis $3 A I$ elements in or outside $R D N 1$. As in sir2::URA3 strains, transposition of Tyl elements outside $R D N 1$ was reduced in sir $3 \Delta$ strains, as a result of the derepression of the $H M$ loci. However, in contrast to sir2 mutants, no increase in transposition of Tyl elements in RDN1 was observed (data not shown). Thus, derepression of rDNA-Tylhis $3 A I$ transposition in sir2 mutants is not merely a consequence of the a/ $\alpha$ phenotype of these strains.

To determine whether the changes in transposition rates observed in sir 2 mutants reflected alterations in the levels of Tylhis3AI RNA, Northern blot analysis was performed. Total RNA from eight strains was analyzed with probes for Tyl, PYK1, and sense-strand HIS3, to detect Tylhis3AI RNA (Fig. 5). Total Tyl RNA levels in the four sir2::URA3 mutants were significantly decreased relative to levels present in the four SIR2 strains analyzed (Fig. 5). Similarly, the levels of Tylhis3AI RNA in strains with elements outside $R D N 1$ were also reduced in sir2::URA3 mutants (Fig. 5; JC242 and JC273). In contrast, disruption of SIR 2 resulted in considerably increased levels of Tylhis $3 A I$ RNA in strains with elements in $R D N 1$ that are normally silenced transcriptionally (Fig. 5; JC234 and JC272). Thus, the effects of SIR2 disruption on transcript levels of Tylhis $3 A I$ elements located inside or outside RDN1 mirrored the changes in transposition rates, indicating that SIR2 functions in transcriptional silencing of Ty1 elements in RDN1.

\section{Mitotic stability of Ty1 insertions in RDN1 is} dependent on SIR2 and UBC2

Previous work has suggested that Tyl elements are un-

Table 3. Derepression of transposition of Ty1his3AI elements in RDN1

\begin{tabular}{|c|c|c|c|c|}
\hline \multirow[b]{2}{*}{ Strain } & \multirow{2}{*}{$\begin{array}{l}\text { Tylhis3A1 } \\
\text { in RDN1 }\end{array}$} & \multicolumn{2}{|c|}{ Transposition rate ${ }^{a}$} & \multirow{2}{*}{$\begin{array}{c}\text { Ratio of rates } \\
\text { (sir2/SIR2) }\end{array}$} \\
\hline & & SIR2 & $\operatorname{sir} 2$ & \\
\hline $\mathrm{JC} 234$ & yes & $3.5 \times 10^{-9}$ & $2.9 \times 10^{-8}$ & 8 \\
\hline $\mathrm{JC} 272$ & yes & $<5.9 \times 10^{-10}$ & $7.6 \times 10^{-8}$ & $>129$ \\
\hline JC242 & no & $1.5 \times 10^{-7}$ & $1.7 \times 10^{-8}$ & 0.1 \\
\hline \multirow[t]{2}{*}{$\mathrm{JC} 273$} & no & $1.1 \times 10^{-7}$ & $6.4 \times 10^{-9}$ & 0.1 \\
\hline & & HTA1-HTB1 & $h t a 1-h t b 1 \Delta$ & $\begin{array}{l}(h t a 1-h t b 1 \Delta / \\
\text { HTA1-HTB1) }\end{array}$ \\
\hline JC236 & yes & $4.0 \times 10^{-9}$ & $5.9 \times 10^{-8}$ & 15 \\
\hline $\mathrm{IC} 272$ & yes & $2.3 \times 10^{-9}$ & $7.0 \times 10^{-8}$ & 30 \\
\hline JC816 & yes & $<2.0 \times 10^{-10}$ & $4.8 \times 10^{-8}$ & $>240$ \\
\hline $\mathrm{JC} 242$ & no & $3.6 \times 10^{-8}$ & $1.6 \times 10^{-7}$ & 4 \\
\hline \multirow[t]{2}{*}{$\mathrm{JC} 273$} & no & $8.0 \times 10^{-8}$ & $4.9 \times 10^{-7}$ & 6 \\
\hline & & TOP1 & top1s & $\mid$ top $1 \Delta / T O P 1 \mid$ \\
\hline $\mathrm{JC} 234$ & yes & $6.0 \times 10^{-9}$ & $2.4 \times 10^{-8}$ & 4 \\
\hline JC236 & yes & $<4.7 \times 10^{-9}$ & $4.7 \times 10^{-8}$ & $>10$ \\
\hline JC242 & no & $1.5 \times 10^{-7}$ & $1.9 \times 10^{-7}$ & 1 \\
\hline
\end{tabular}

a The rate of $\mathrm{His}^{+}$prototroph formation per cell per generation, as determined by the method of Lea and Coulson (1949). 
Bryk et al.

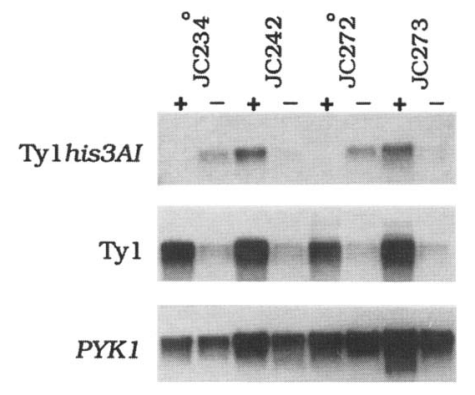

Figure 5. Effect of SIR2 disruption on Tyl his $3 A I$ and total Tyl RNA levels. Total RNA from isogenic SIR2 $(+)$ and sir2::URA3 (-) strains containing single Tylhis $3 A I$ insertions was subjected to Northern blot analysis. The blot was hybridized to a sensestrand HIS 3 riboprobe to detect Tylhis $3 A I$ transcript (top), an antisense Tyl riboprobe to detect total Tyl transcript (middle), and an antisense PYK1 riboprobe as a loading control (bottom). Strains with Tylhis $3 A I$ insertions in $R D N 1$ are marked with a superscript o. The sir2/SIR2 ratio of Tylhis3AI RNA normalized to PYK1 RNA, as determined by scanning densitometry is JC234 ${ }^{\circ}, 89.0$; JC242, 0.16; JC272 ${ }^{\circ}, 78.9$; JC273, 0.04.

derrepresented and may be mitotically unstable in RDN1 (Petes 1980), which could explain their low levels of transposition. To test the mitotic stability of de novo Tyl insertions in $R D N 1$, a HIS3 allele was introduced into strains containing Tyl his $3 A I-234,-236,-242,-272$, and -820 by gene disruption of the Tylhis $3 A I$ element. We then tested for loss of the HIS3 marker in the Tyl element in each strain, after growth for $\sim 120$ generations in nonselective YPD medium. A His ${ }^{-}$phenotype could result from loss of the HIS3 marker by recombination between rDNA repeats, recombination between LTRs, by ectopic recombination with an unmarked Tyl element, or from transcriptional silencing of the HIS3 gene. Interestingly, no more than $3.8 \times 10^{-4} \mathrm{His}^{-}$colonies per generation arose in strains containing RDN1 elements TylHIS3-234, -236, -272, and -820 (Table 4). This rate of loss of the $\mathrm{His}^{+}$phenotype was equivalent to that of the element TylHIS3-242, located outside RDN1 on chromosome XII. The stability of the HIS3 marker in these strains was not attributable to a selective growth advantage of $\mathrm{His}^{+}$cells in YPD broth, as mixed cultures of the His $^{-}$strain harboring Tylhis $3 A I-242$ and the isogenic His $^{+}$strain containing Ty1HIS3-242 had only a slight decrease in the fraction of $\mathrm{His}^{-}$cells over 120 generations of growth (Table 4). In addition, we found that three TylADE2 insertions in the NTS and three control TylADE2 insertions outside RDN1 had equivalent frequencies of loss of the $\mathrm{Ade}^{+}$phenotype after nonselective growth for $\sim 100$ generations (data not shown). Hence, the mitotic stability of Ty1 insertions in RDN1 indicates that their low level of transcription is not attributable to rapid loss of the Tyl insertion from the rDNA array. Furthermore, mitotic instability of Tyl elements probably does not explain their underrepresentation in RDN1 in typical yeast strains. Significantly, these findings also indicate that HIS3 and ADE2 marker genes in Tyl are not subject to position effect in $R D N 1$, even after prolonged nonselective growth.

To determine whether the mitotic stability of Tyl insertions is altered in sir2 mutants, we measured the rate of loss of Ty1HIS3 elements within (-234 or -272) or outside (-242) RDN1 in sir2 strains (Table 4). Loss of the HIS3 marker from RDN1 was increased 7.8-fold (Ty1HIS3-234) and 12.6-fold (TylHIS3-272) in isogenic sir2 derivatives compared to SIR2 strains. However, the mitotic stability of TylHIS3-242, located outside RDN1,

Table 4. Mitotic stability of Ty1HIS3 elements in RDN1

\begin{tabular}{|c|c|c|c|c|}
\hline Ty1 element (in $R D N 1)$ & $\begin{array}{l}\text { Relevant } \\
\text { strain genotype }\end{array}$ & $\begin{array}{l}\text { Number of } \mathrm{His}^{-} \text {auxotrophs/ } \\
\text { total number of cells } \\
\text { analyzed (fraction) }\end{array}$ & $\begin{array}{l}\text { HIS3 loss/ } \\
\text { generation }\end{array}$ & $\begin{array}{l}\text { Loss relative } \\
\text { to } \mathrm{WT}\end{array}$ \\
\hline \multirow[t]{3}{*}{ TylHIS3-234 (yes) } & WT & $102 / 2324(0.044)^{b}$ & $3.7 \times 10^{-4}$ & - \\
\hline & $\operatorname{sir} 2$ & $176 / 498\{0.353\}$ & $2.9 \times 10^{-3}$ & 7.8 \\
\hline & $u b c 2 \Delta$ & $281 / 1550\{0.181\}$ & $1.5 \times 10^{-3}$ & 4 \\
\hline TylHIS3-236 (yes) & WT & $0 / 296(<0.003 \mid$ & $<2.8 \times 10^{-5}$ & - \\
\hline \multirow[t]{3}{*}{ TylHIS3-272 (yes) } & WT & $127 / 2749(0.046)^{\mathrm{b}}$ & $3.8 \times 10^{-4}$ & - \\
\hline & $\operatorname{sir} 2$ & $204 / 355(0.575)$ & $4.8 \times 10^{-3}$ & 12.6 \\
\hline & $u b c 2 \Delta$ & $334 / 913(0.366)$ & $3.0 \times 10^{-3}$ & 7.9 \\
\hline TylHIS3-820 (yes) & WT & $1 / 66(0.015)$ & $1.3 \times 10^{-4}$ & - \\
\hline \multirow[t]{3}{*}{ TylHIS3-242 (no) } & WT & $124 / 2760(0.045)^{\mathrm{b}}$ & $3.7 \times 10^{-4}$ & - \\
\hline & sir2 & $10 / 189(0.053)$ & $4.4 \times 10^{-4}$ & 1.2 \\
\hline & $u b c 2 \Delta$ & $85 / 1305(0.065)$ & $5.4 \times 10^{-4}$ & 1.5 \\
\hline \multicolumn{5}{|l|}{ Tylhis $3 A I-242+$} \\
\hline TylHIS3-242 ${ }^{\mathrm{c}}$ (no) & WT & $1024 / 1838(0.557)^{\mathrm{b}}$ & N.A. & - \\
\hline
\end{tabular}

(WT) Wild type. (N.A.) Not applicable.

${ }^{a}$ Determined after 120 generations of nonselective growth in YPD broth.

${ }^{\mathrm{b}}$ Average of three independent cultures.

${ }^{\mathrm{c}}$ Three mixed cultures of isogenic His ${ }^{-}$(Tylhis3AI-242) and His ${ }^{+}$(TylHIS3-242) strains were analyzed to determine whether His ${ }^{+}$cells had a growth advantage in nonselective medium. The Tylhis3AI-242 + TylHIS3-242 cultures contained a fraction of $1008 / 1705(0.591)$ $\mathrm{His}^{-}$cells prior to growth on YPD broth. 
was unaltered in a sir2 derivative. Significantly, the results in Table 4 demonstrate that like SIR2, UBC2 also suppresses mitotic recombination in $R D N 1$. In $u b c 2 \Delta$ strains, the rate of loss of the HIS3 marker in RDN1 increased 4-fold (TylHIS3-234) and 7.9-fold (TylHIS3272), whereas loss of the HIS 3 marker outside RDN1 (Ty1HIS3-242) was not altered significantly. To summarize, our results are consistent with the previous report that SIR2 regulates mitotic recombination at RDN1 (Gottlieb and Esposito 1989). Moreover, these results uncover a second novel function for $U B C 2$ in suppression of mitotic recombination at $R D N 1$.

\section{Depletion of histones $\mathrm{H} 2 \mathrm{~A}-\mathrm{H} 2 \mathrm{~B}$ abolishes silencing of Ty1his3AI elements in RDN1}

If positional silencing of Ty1 elements in RDN1 is occurring through the effect of a repressive chromatin structure, then perturbations in nucleosome structure might be expected to disrupt silencing. Therefore, deletion of HTA1-HTB1, one of two loci that encodes histones $\mathrm{H} 2 \mathrm{~A}$ and $\mathrm{H} 2 \mathrm{~B}$, might reveal a role for chromatin structure in silencing of Tyl transcription in RDN1. Significantly, histones $\mathrm{H} 2 \mathrm{~A}$ and $\mathrm{H} 2 \mathrm{~B}$ have also been shown to be targets for the $U B C 2$ ubiquitin-conjugating activity in vitro (Sung et al. 1988).

The HTA1-HTB1 locus was deleted in strains containing Tylhis $3 A I$ elements both in and outside RDN1. Transposition of Tylhis $3 A I$ elements outside RDN1 in-

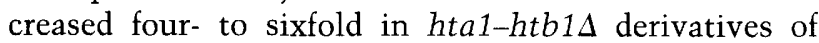
strains JC242 and JC273. In contrast, the transposition rates of Tylhis $3 A I$ elements in RDN1 increased dramatically from 15 -fold (strain JC236) to $>240$-fold (strain JC816) in the isogenic hta1-htb1s derivatives (Table 3). Thus, alterations in the levels of histones $\mathrm{H} 2 \mathrm{~A}$ and $\mathrm{H} 2 \mathrm{~B}$ cause a modest increase in transposition of Tylhis $3 A I$ elements located outside $R D N 1$, but a far greater enhancement of transposition is seen for Tylhis $3 A I$ elements in RDN1. The higher transposition rates in hta1htb1S mutants are accompanied by increases in Tyl his $3 A I$ and total Tyl RNA transcript levels (data not shown). In summary, these results suggest that silencing of Tyl elements in RDN1 is the result of a specialized chromatin structure at $R D N 1$, which may involve packaging of the DNA into a stable nucleosome structure.

\section{Topoisomerase I mediates silencing of Ty1 elements in $\mathrm{RDN} 1$}

Topoisomerase I has been shown to suppress mitotic recombination between rDNA repeats and to maintain the chromatin structure of RDN1 (Christman et al. 1988, 1993; Cavalli et al. 1996). We were interested to determine whether the function of topoisomerase I at $R D N 1$ influenced expression of Tylhis $3 A I$ elements in RDN1. Therefore, the TOP1 gene was deleted from strains with Tylhis $3 A I$ insertions in and outside of RDN1. As shown in Table 3, the transposition rates of Tylhis $3 A I$ elements in RDN1 increased 4-fold (strain JC234) to 10-fold (strain JC236) in top1s derivatives, whereas the transpo- sition rate of the element outside $R D N 1$ stayed the same (strain JC242). The higher transposition rates in top1A mutants are the result of an increase in Tyl his $3 A I$ transcript levels from elements in RDN1 (data not shown). Our results suggest that the role of TOP1 in maintaining the chromatin structure of the rDNA array is required for transcriptional silencing of Tyl elements and further support the model that the RDN1 locus has a unique chromatin structure that is repressive to both mitotic recombination and Tyl transcription.

\section{Discussion}

We have demonstrated transcriptional silencing of five different Ty1 retrotransposons that integrated in varied positions in RDN1, resulting in repression of their transcription and therefore, transposition. Moreover, a unique set of trans-acting modifiers, UBC2, SIR2, HTA1-HTB1, and TOP1, silence transcription of Tyl elements in RDN1 but do not affect significantly Tyl elements outside $R D N 1$, supporting a model whereby silencing results from a specialized chromatin structure at $R D N 1$. Our results reveal novel features of position-dependent silencing at RDN1 and differentiate the mechanism of RDN1 silencing from other types of position effect seen at the $H M$ loci and telomeres.

\section{Ty1his3AI elements in $r D N A$ are silenced by a specialized chromatin structure}

Tyl his $3 A I$ elements in $r D N A$ have rates of transposition ranging from 10- to $>100$-fold lower than a typical active Tyl his $3 A I$ element located outside RDN1, such as the one in strain JC242 (Table 1). The variation in silencing may be attributable to differences in the position of Tyl elements in the rDNA repeat (Fig. 2C) or in the rDNA array (Fig. 3C), although no simple correlation was observed. Alternatively, inherent cis-acting differences in the individual Tyl his $3 A I$ elements themselves could account for their different transposition rates. Interestingly, however, the magnitude of transcriptional derepression seen in $u b c 2 \Delta$, sir2, hta1-htb1s, and top $1 \Delta \mathrm{mu}-$ tants is related to the strength of silencing for each individual element in the rDNA array. For example, Tylhis3AI-234 transposition is derepressed 11-, 8-, and 4-fold in $u b c 2 \Delta$, sir2, and top $1 \Delta$ mutants, respectively, whereas the more strongly silenced element Tyl his $3 A I$ 272 is derepressed $>73-,>129-$, and 30-fold in $u b c 2 \Delta$, sir2, and hta1-htb1s mutants, respectively (Tables 1 and 3 ). Thus, the data support a model in which UBC2, SIR2, HTA1-HTB1, and TOP1 participate in a common mechanism to mediate transcriptional silencing of Tyl elements in RDN1.

The UBC2, SIR2, HTA1-HTB1, and TOP1 gene products have all been implicated previously in other modifications of chromatin or DNA structure, and their role in transcriptional silencing in $R D N 1$ is likely to be related to these other functions. SIR2 is required for positional silencing of repeated regions in the yeast genome, a process that entails formation of a heterochromatin- 
like DNA structure. Overexpression of Sir2p has been shown to lead to deacetylation of histones and as nucleosomes at the $H M$ loci are hypoacetylated, the proposal has been made that Sir $2 p$ is associated with hypoacetylation of silent regions (Braunstein et al. 1993, 1996). In addition, SIR2 and TOP1 repress recombination in RDN1 (Christman et al. 1988; Gottlieb and Esposito 1989 ) and in this work, we show that UBC2 has the same effect (Table 4). TOP1 is required to maintain the normal physical structure of the RDN1 locus (Christman et al. 1993), and top 1 mutants show increased psoralen accessibility in transcribed rDNA (Cavalli et al. 1996).

A definitive role for chromatin structure in silencing of Tyl transcription was revealed by a dramatic increase in rDNA-Tylhis3AI transposition in hta1-htb1s mutants (Table 3). Deletion of HTA1-HTB1 results in depletion of the H2A-H2B dimer from nucleosomes, which is proposed to destabilize nucleosomes by weakening the contacts between histones and DNA (Lee et al. 1993). Hence, transcription is thought to be altered in hta1$h t b 1 \Delta$ mutants at loci where positioned nucleosomes are components of transcriptional regulation. For instance, nucleosome positioning in $h t a 1-h t b 1 \Delta$ mutants is not altered at HIS4 and Tyl LTRs, but is changed dramatically at centromeres $C Y H 2$ and $U B I 4$, indicating that nucleosome integrity can play a critical role in regulation of transcription of certain genes (Norris et al. 1988). Smith and Boeke (this issue) show in an accompanying manuscript that a silenced mURA3 marker within an rDNA repeat is no longer subject to transcriptional silencing when the rDNA repeat is placed outside of the $R D N 1$ locus. Their data argue against the interpretation that rDNA contains a cis-acting silencer of Pol II genes. Hence, the data strongly suggest that the rDNA array adopts a specific chromatin structure that is repressive to certain Pol II genes, including Tyl elements.

Several features of the RDN1 locus are analogous to domains of heterochromatin, including the presence of tandemly repeated DNA sequences containing ARS elements, which have been shown to be involved in maintenance of position effect in yeast. Furthermore, suppression of recombination is a common feature of heterochromatin domains in other organisms. The involvement of SIR2 suggests that the mechanism of transcriptional repression at $R D N 1$ shares some aspects of position effect at the telomeres and $H M$ loci. On the other hand, differences between heterochromatic regions in yeast and the RDN1 locus suggest that there are different pathways of establishing chromatin structures that are repressive to transcriptional and recombinational processes. At telomeres and the $H M$ loci, Sir $4 p$ is known to interact with Sir $2 p, \operatorname{Sir} 3 p$ and the amino-terminal tails of the histone $\mathrm{H} 3$ and $\mathrm{H} 4$. However at RDN1, transcriptional silencing of Tyl requires the Sir2 protein and histones $\mathrm{H} 2 \mathrm{~A}$ and $\mathrm{H} 2 \mathrm{~B}$, but does not require Sir3p. Furthermore, Smith and Boeke (1997) show that silencing of other Pol II genes in the rDNA array does not require Sirlp, Sir3p, or Sir $4 p$. In addition, chromatin at telomeres and the $H M$ loci has been shown to be inaccessible to DNA-modifying enzymes, whereas the
RDN1 locus is partially accessible to dam methylase in wild-type strains (M. Bryk and M.J. Curcio, unpubl.). These results agree with the partial accessibility of rDNA to psoralen cross-linking (Cavalli et al. 1996; Smith and Boeke 1997). Perhaps the need for transcription by Pol I and Pol III necessitates formation of a more accessible type of chromatin at $R D N 1$ that is repressive to Pol II transcription. One possibility is that the locus is packaged in stabilized nucleosomes that can be repositioned by Pol I and Pol III transcription factors but restrict access preferentially to Pol II transcription factors and mediators of recombination.

\section{The $\mathrm{UBC} 2$ protein is a regulator of chromatin structure in RDN1}

The UBC2 gene encodes an E2-ubiquitin-conjugating enzyme that is involved in many cellular processes including DNA repair, damage-induced mutagenesis, $\mathrm{N}$ end rule protein degradation, growth control, sporulation, and Tyl integration specificity. Ubc2p has been shown to form a specific complex with the E3 protein Ubrlp to mediate $\mathrm{N}$-end rule protein degradation (Madura et al. 1993) and a second complex with the single-stranded DNA-binding protein Rad18p, which is thought to function in DNA repair (Bailly et al. 1994).

Theoretically, the role of $U B C 2$ in $\mathrm{N}$-end rule degradation could explain the observed transcriptional repression if there was a limiting factor for a cryptic Pol II enhancer in $R D N 1$ whose concentration is increased in ubc2s mutants. However, rDNA-Tylhis $3 A I$ transposition is repressed in strains containing $u b c 2-149$ and $u b c 2-153$ alleles and in $u b r 1$ mutants, all of which are defective in $\mathrm{N}$-end rule degradation (Table 2; data not shown). Hence, $\mathrm{N}$-end rule degradation is not involved in transcriptional silencing of Tyl elements in rDNA. Furthermore, the existence of a limiting factor required for Tyl transcription is not supported by our findings that $U B C 2$ is involved in two silencing processes at $R D N 1$, transcriptional repression of de novo Tyl insertions (Table 1; Figure 4) and suppression of mitotic recombination (Table 4).

There are at least two basic models for the involvement of $U B C 2$ in formation of a chromatin conformation at RDN1 that is repressive to Pol II transcription and recombination. First, Ubc2p may alter the chromatin structure of $R D N 1$ indirectly through its ability to ubiquitinate cellular proteins. Ubiquitinization of target proteins by Ubc2p may facilitate the formation of higherorder chromatin structure at $R D N 1$ or alter the repressive effect of individual nucleosomes. Potential substrates for ubiquitinization by Ubc2p include the histones $\mathrm{H} 2 \mathrm{~A}$ and $\mathrm{H} 2 \mathrm{~B}$, as $\mathrm{Ubc} 2 \mathrm{p}$ has been shown to ubiquitinate these histone proteins in vitro (Jentsch et al. 1987; Sung et al. 1988). The function of ubiquitinization of $\mathrm{H} 2 \mathrm{~A}$ and $\mathrm{H} 2 \mathrm{~B}$ in yeast has not been established, as deletion of a potential ubiquitinization site that is conserved in higher eukaryotes results in none of the DNA repair, mutagenesis, growth, or sporulation defects associated with ubc2s mutants (Swerdlow et al. 1990). How- 
ever, alteration of chromatin in $R D N 1$ would result in a subtle phenotype that probably would not have been detected. By examining the transposition phenotype of Tyl elements in $R D N 1$ in strains with an $h t a 1-h t b 1$ allele lacking the proposed ubiquitinization site, we will be able to test this model. Alternatively, Ubc2p may ubiquitinate a non-nucleosomal protein that mediates the formation of a repressive chromatin structure, as has been suggested for the deubiquitinating protein Ubp3p, which interacts with Sir4p (Moazed and Johnson 1996).

A model in which the $U B C 2$ protein modifies a component of chromatin in RDN1 can explain both the positional silencing of Tyl elements and the suppression of rDNA recombination. Several other observations also implicate the ubiquitin-conjugating activity of $U B C 2$ in the modification of chromatin function. First, mutations in $u b c 2$ have been shown to increase Tyl integration into Pol II ORFs and to randomize its target specificity (Picologlou et al. 1990; Liebman and Newnam 1993). This has been interpreted as indicative of a change in chromatin assembly in Pol II ORFs, and our results support this paradigm. As observed previously, total Tyl RNA levels are not increased in $u b c 2 \Delta$ mutants (Fig. 4), and no increase in Tylhis $3 A I$ transposition is observed unless it is accompanied by an increase in transcription of a specific silenced element (Table 1). Thus, increased targeting to ORFs is not the result of more efficient transposition per Ty1 RNA in $u b c 2$ mutants. Instead, local alterations in chromatin structure may allow ORFs, which are normally poor integration targets, to be used more frequently in $u b c 2$ mutants. Second, a recent paper has reported that mice with a disruption in a $U B C 2$ homolog exhibit defects in condensation of chromatin during spermatogenesis (Roest et al. 1996). Interestingly, the sporulation defects of $u b c 2$ mutants have also been proposed to result from improper chromatin condensation (Lawrence 1994). The involvement of $U B C 2$ and its mouse homolog in these processes suggests a role for $U B C 2$ in chromatin remodeling. Third, Moazed and Johnson (1996) have shown that Ubp3p, an enzyme that deubiquitinates target proteins, is an inhibitor of position-dependent transcriptional silencing at the $H M$ loci and telomeres. Their results indicate that ubiquitinization can enhance silencing in yeast and support a role for ubiquitinization in regulation of chromatin structure.

A second model to explain the role of $U B C 2$ in a repressive chromatin structure in RDN1 is that Ubc2p interacts directly with DNA in the RDN1 locus. UBC2 functions with $R A D 9, R A D 18$, and other genes in an "error-free" DNA repair pathway, which is involved in repairing single-stranded regions formed by incomplete DNA replication or certain recombination events (Lawrence 1994). Domains of single-stranded DNA may be common in RDN1, given the high occurrence of sister-chromatid exchange and gene conversion. In the absence of $U B C 2$, repair at $R D N 1$ may be slowed and/or replacement repair functions may be recruited, resulting in a block to reformation of the specialized chromatin structure in $R D N 1$. There is a precedent for disruption of chromatin structure during defective damage repair, as expression of a silenced telomeric URA3 gene is stimulated in the absence of $R A D 7$, which encodes an accessory for the nucleotide-excision repair pathway (Paetkau et al. 1994). This second model can be tested by analyzing the effect of other genes implicated in the error-free DNA repair pathway on transcriptional silencing and suppression of recombination in RDN1.

\section{A role for integration into $\mathrm{RDN1}$ in the regulation of Ty1 transposition}

The expression of Tyl appears to be more sensitive to the effects of chromatin structure in $R D N 1$ than other Pol II-transcribed genes. Expression of Tylhis $3 A I$ elements in RDN1 is barely detectable in our Northern analysis and transposition assays. Interestingly, however, there appears to be no repression of the marker gene. That is, when the his $3 A I$ gene within the Tyl element is replaced with HIS3, it is expressed, even after 120 generations of nonselective growth. Similarly, no evidence of variegated expression of an $A D E 2$ marker gene was observed in colonies after 100 generations of nonselective growth of strains containing TylADE2 insertions in RDN1. The stability of marker genes in $R D N 1$ that are outside the context of Tyl has been documented previously (Szostak and Wu 1980; Gottlieb and Esposito 1989). Consistent with the absence of a upstream activating sequence (UAS) in the Tyl promoter, the potency of position effect at RDN1 may reflect promoter strength. Indeed, the degree of silencing of expression near telomeres is determined primarily by the strength of a gene's promoter (Renauld et al. 1993). Smith and Boeke (1997) have shown that a URA3 gene with a minimal trp1 promoter (mURA3), the MET15 gene, and the LEU2 gene are also subject to position effect in RDN1, which is relieved by disruption of SIR2.

The fact that the RDN1 locus is an efficient target for Tyl integration could play an important role in the regulation of Tyl transposition, as Tyl insertions in RDN1 are phenotypically silent. Because Tylhis $3 A I$ insertions are present in a single copy of the rDNA repeat (Fig. 3), their presence is unlikely to have any deleterious consequences. Moreover, they are significantly more likely to be lost rather than amplified by the unequal recombinational processes that predominate in RDN1. Tyl elements in $R D N 1$ are also very poorly expressed and therefore, do not contribute significantly to the overall rate of transposition in the cell. Studies with Tyl elements fused to the GAL1 promoter have established that a modest increase in Tyl RNA can overcome a post-translational block that is responsible for maintaining transpositional dormancy (Boeke et al. 1985; Curcio and Garfinkel 1992). Therefore, transposition into RDN1 could play a role in the regulation of transposition by acting as a domain where Ty1 elements can insert without creating deleterious mutations or causing total Tyl RNA to increase above a level that would overcome transpositional dormancy. Considering this, it is notable that Tyl elements are underrepresented in the rDNA in 
typical yeast strains, despite the fact that we have shown that Tyl elements are targeted efficiently to the rDNA array and are mitotically stable in $R D N 1$ relative to Ty1 elements located elsewhere. Hence, it may be that the rDNA array is used more efficiently at times when Tyl transcription is elevated, such as during induction by GAL1:Tyl overexpression or during exposure to DNAdamaging agents. This hypothesis can be tested by quantitating transposition into the rDNA array during growth under different environmental conditions.

\section{Materials and methods}

Yeast strains

All yeast strains used in this study are congenic derivatives of GRF167 (MAT $\alpha$, his3 2200 , ura3-167) (Boeke et al. 1985), except

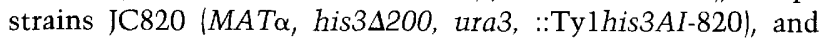
JC821 (MATa, his3 200 , ade2-101, leu2A, ura3, ::Ty1his3AI821). Strains JC234 (::Ty1 his3AI-234), JC236 (::Tyl his $3 A I-236)$, JC242 (::Ty1his3AI-242), JC272 (::Ty1his3AI-272), JC273 (::Tylhis3AI-273), JC815 (::Tylhis3AI-815), and JC816 (::Tylhis $3 A I-816)$ were isolated after galactose-induction of plasmid pGTy1-H3mhis $3 A I$ in strain GRF167, as described previously (Curcio and Garfinkel 1991b). The presence of a single genomic Tylhis $3 A I$ transposition event was demonstrated by Southern blotting with a HIS3 probe. Strains JC820 and JC821 are ascospores of a cross between an spt3-101 derivative of GRF167 containing Tylhis3AI transposition events. Strain JSS104-32A (MATa, ade2-101, his3 $\Delta 200$, leu2- $\Delta 1$, ura3-52) was kindly provided by J.N. Strathern (NCI-FCRDC, Frederick, MD).

Isogenic derivatives of strains GRF167, JC234, JC236, JC242, JC272, JC815, JC816, JC820, and JC821 harboring the $u b c 2 \Delta::$ his $G$ allele were constructed by integrative transformation using plasmid pJ)313, as described previously (Curcio and Garfinkel 1994).

The his $3 A I$ gene was replaced with HIS3 by transforming strains JC234, JC236, JC242, JC272, and JC820 with a 0.83-kb ClaI fragment of pGEM-HIS3 (Curcio and Garfinkel 1992), and selecting for $\mathrm{His}^{+}$transformants. The presence of a TylHIS3 allele was confirmed by Southern analysis.

The SIR2 gene was disrupted in strains JC234, JC242, JC272, and JC273 by integrative transformation, using the $4.9-\mathrm{kb}$ XbaI-Xhol fragment of pBST KS+ sir2::URA3gb (see below). The sir2::URA3 disruptions were verified by a nonmating phenotype and Southern analysis. The mating-type of each of the four strains was switched from $\alpha$ to a/ $\alpha:: U R A 3$ by two-step gene disruption using plasmid pSC11, a URA3-based plasmid containing MATa (Adams et al. 1995). Subsequently, the mating type was switched to a by selection for 5-fluoro-orotic acid (5-FOA)-resistant derivatives of the a/ $\alpha$ haploids.

The HTA1-HTB1 locus encoding histones $\mathrm{H} 2 \mathrm{~A}$ and $\mathrm{H} 2 \mathrm{~B}$ was disrupted in strains JC236, JC242, JC272, JC273, and JC816 by integrative transformation of the EcoRI-MscI fragment of pUC9 $\triangle \operatorname{trt} 1:: U R A 3$ (Norris and Osley 1987). The hta1htb1 $1:$ URA3 disruptions were verified by Southern analysis.

The TOP1 gene was disrupted in $\operatorname{trp} 1 \Delta$ derivatives of JC236, JC242, JC272, and JC273 by integrative transformation of the NcoI-PstI fragment of pTP1-4 topl $\Delta:: T R P 1$. The top1 disruptions were verified by Southern analysis. Plasmid pTP1-4 top $1 \Delta:: T R P 1$ was generously provided by $M$. Bjornsti (Thomas Jefferson University, Philadelphia, PA).

Plasmid construction

Plasmid pBST KS + sir2 was constructed by ligating a 1063-bp $B a m H I-E c o$ RV fragment generated by PCR amplification of the
SIR2 gene from strain GRF167 using oligomers sir2 5.1 (CCGAGTGATCAAGATAACG) and sir2 3' (CGTTCCATTTCTTATGCGG) into the BamHI-EcoRV interval of the pBST KS+ (Stratagene). Plasmid pBST KS+ sir2::URA3gb was constructed by ligating the 3.8-kb BamHI-BglII hisG-URA3-hisG fragment from plasmid pNKY51 (Alani et al. 1987) into the unique BglII site in SIR2 sequences of pBST KS+ sir2.

\section{Transposition assays}

Transposition rates in strains containing Tylhis $3 A I$ elements were determined by the maximum likelihood method of Lea and Coulson (1949). Strains were grown to saturation in YPD medium at $30^{\circ} \mathrm{C}$. For each strain, 9 or 11 tubes containing $2 \mathrm{ml}$ of YPD medium were inoculated with $\sim 500$ cells and grown to saturation at $20^{\circ} \mathrm{C}$. For $H T A 1-H T B 1$ and $\Delta h t a 1-h t b 1$ strains, after dilution of cells into YPD, the cultures were grown at $24^{\circ} \mathrm{C}$ because the $\Delta h t a 1-h t b 1$ strains exhibit a severe growth defect at $20^{\circ} \mathrm{C}$. Three cultures were titered on YPD plates, and all cultures were plated to synthetic complete medium lacking histidine (SC-His) and grown at $30^{\circ} \mathrm{C}$ to quantify $\mathrm{His}^{+}$prototrophs. In all cases, UBC2 and $u b c 2 \Delta:: h i s G$, SIR2, and sir2::URA3, HTA1-HTB1, and $\Delta h t a 1-h t b 1$, or TOP1 and top $1 \Delta$ isogenic pairs were tested in the same experiment.

For complementation experiments, strains JC236ubc2 $\Delta$ and $\mathrm{JC} 272 u b c 2 \Delta$ were transformed with YCp50, a URA3-based CEN vector, or derivatives carrying $U B C 2, u b c 2-149, u b c 2-153$ (plasmid pR67, pR615, and pR616, respectively; Morrison et al. 1988) or $u b c 2_{\Delta 1-9}$ (plasmid pR68; Watkins et al. 1993). Plasmids carrying $U B C 2$ alleles were generously provided by L. Prakash (University of Texas, Galveston). Plasmid-containing strains were grown to saturation in SC-Ura medium. For each strain, 11 tubes containing $2 \mathrm{ml}$ of SC-Ura medium were inoculated with $\sim 500$ cells and grown to saturation at $20^{\circ} \mathrm{C}$. The cultures were titered on SC-Ura and plated to SC-Ura-His to quantify $\mathrm{His}^{+} \mathrm{Ura}^{+}$prototroph formation.

\section{CHEF gel analysis}

Agarose-embedded genomic DNA was prepared from $1 \mathrm{ml}$ of an overnight culture in YPD medium (Gerring et al. 1991). In the case where genomic DNA was subject to digestion with BamHI, plugs were preincubated in PMSF, and then incubated with 40 units of enzyme for $15 \mathrm{hr}$ at $37^{\circ} \mathrm{C}$. Using a BioRad CHEF Mapper apparatus, samples were separated by electrophoresis on a $1 \%$ agarose gel (SeaKem Gold) in $0.5 \times \mathrm{TBE}$ buffer at $14^{\circ} \mathrm{C}$ using 200 $\mathrm{V}$ and $50-$ to $90-\mathrm{sec}$ pulse times for $24 \mathrm{hr}$. The gel was stained with ethidium bromide and photographed. After UV irradiation for 2 min in a Spectrolinker (Spectronics), DNA was transferred onto a Hybond-N+ membrane (Amersham) and probed with a HIS3 riboprobe synthesized as described below. The probe was stripped from the blot in $0.4 \mathrm{~N} \mathrm{NaOH}$ at $37^{\circ} \mathrm{C}$ and rehybridized to an $R D N 1$ riboprobe synthesized from pGEM-18S, which contains an EcoRI fragment of the $18 \mathrm{~S}$ rDNA gene cloned into pSP70 (Promega). The sizes of rDNA-hybridizing BamHI fragments (Fig. 3) were estimated from Lambda Ladder standards (Bio-Rad) and added to determine the total size of RDN1. For strains JC234 and JC236, the RDN1 locus was estimated to be $1900 \mathrm{~kb}$. Variability in the sizes of the RDN1 locus and its fragments was noted in repeats of these experiments. This is not unexpected as the size of $R D N 1$ can vary during cell growth (Olson 1991).

\section{Isolation and sequencing of DNA flanking Ty1his3AI insertions}

The $3^{\prime}$ end of Tyl his $3 A I$ insertions and flanking genomic DNA was cloned by the integration and eviction method of Winston 
et al. (1983). Plasmid pGEM-HIS3 contains an 890-bp fragment of the yeast HIS3 gene (Garfinkel et al. 1988) subcloned into pSP70 (Promega). The plasmid was linearized within HIS3 by NheI and transformed into yeast strains JC234, JC236, JC242, JC272, JC815, JC816, and JC820 by the lithium acetate method (Gietz et al. 1992). His ${ }^{+}$plasmid integrants were single-colony purified. To evict pGEM-HIS3 and sequences flanking the Tylhis3AI element, $100 \mathrm{ng}$ of genomic DNA prepared from independent $\mathrm{His}^{+}$transformants was digested with AatII, which cleaves once in pGEM-HIS3 but not in his3AI or the Tyl-LTR. The resulting AatII fragment contains vector sequences, the $3^{\prime}$ LTR, and flanking genomic DNA. AatII-digested DNA was phenol extracted, ethanol precipitated, resuspended in $1 \times$ TE buffer $(\mathrm{pH} 81$, and 1 of $50 \mu \mathrm{l}$ was ligated in a $20-\mu 1$ reaction. Ligations were used to transform Escherichia coli strain DH5 to ampicillin resistance. The presence of a 0.45-kb BamHI fragment of his $3 A I$ in plasmid evictants from three independent $\mathrm{His}^{+}$prototrophs was used to verify eviction of the Tylhis $3 A I$ junction fragment. DNA sequencing from the 3' LTR was performed using the oligomer AX009 (CTTTATCAACAATGGAATCCC) and Sequenase, version 2.0 (U.S. Biochemical).

\section{Assay for mitotic stability of Ty1HIS3 elements}

The his3AI marker in strains JC234, JC236, JC242, JC272, and JC820 was replaced with a HIS3 marker by integrative transformation. A single colony of each $\mathrm{His}^{+}$transformant was taken from SC-His medium and used to inoculate $10 \mathrm{ml}$ of YPD medium. In addition, single colonies of the His ${ }^{-}$auxotroph JC242 (pregrown on YPD) and the TylHIS3 derivative of JC242 were mixed in $10 \mathrm{ml}$ of YPD medium. An aliquot of the JC242+JC242-Ty1HIS3 mixed culture was plated onto YPD medium, and then replicated to $\mathrm{SC}-\mathrm{His}$ medium to determine the fraction of $\mathrm{His}^{-}$colonies before prolonged growth in nonselective medium. All cultures were grown overnight at $30^{\circ} \mathrm{C}$. One microliter of each culture was then diluted into $10 \mathrm{ml}$ of fresh YPD and grown to stationary phase $(32-40 \mathrm{hr})$ at $30^{\circ} \mathrm{C}$. The $1: 10,000$ dilution was repeated a total of eight times. Cells from the ninth serial culture were plated onto YPD plates, and replicated to determine the fraction of $\mathrm{His}^{-}$auxotrophs.

\section{Northern blot analysis}

Yeast strains were grown overnight in YPD medium at $30^{\circ} \mathrm{C}$ to saturation, and then diluted 1:25 in fresh YPD, except for $u b c 2 \Delta::$ his $G$ strains, which were diluted $1: 12.5$, and all were grown at $20^{\circ} \mathrm{C}$ for $4 \mathrm{hr}$ to exponential phase. Total RNA was isolated from $5 \times 10^{8}$ to $7 \times 10^{8}$ cells as described by Schmitt et al. (1990). RNA samples were denatured by treatment with glyoxal as described previously (Curcio et al. 1990), separated by electrophoresis in $1 \%$ agarose (SeaKem Gold, FMC), and transferred to Hybond-N nylon membrane (Amersham). Radiolabeled RNA probes were synthesized in vitro using Riboprobe Gemini System II (Promega). Plasmids pGEM-HIS3, pGEMPYK1, and pGEM-Ty1A (Curcio and Garfinkel 1992) were used as templates for in vitro transcription of sense-strand HIS3 and antisense-strand PYK1 and Tyl probes, respectively. Northern blots were quantified by scanning densitometry using a Howtek Scanmaster 3+ scanner and Scanalytics software. Tylhis $3 A I$ RNA levels normalized to PYK1 RNA were determined for each strain and the ratio of Tylhis $3 A I / P Y K 1$ RNA for each strain pair is reported in the legends to Figures $4(u b c 2 \Delta / U B C 2)$ and 5 (sir2/SIR2). The ratio of PYK1 RNA to rRNA (as determined by ethidium staining of RNA) was not significantly altered by $u b c 2 \Delta$.

\section{Acknowledgments}

We are grateful to M. Belfort, J. Boeke, D. Conte, K. Madura, R. Morse, J. Mueller, J. Smith, and J. Strathern for helpful comments on the manuscript, to J. Dalgaard for expert advice on computer analysis of sequences, and to the Molecular Genetics Core Facility for oligomer synthesis. We are grateful to J. Smith and J. Boeke for sharing information before to publication. This work was funded by National Institutes of Health grant GM52072 to M.J.C. and American Cancer Society postdoctoral fellowship PF-4244 to M. Bryk. The research of D.J.G. was sponsored by the National Cancer Institute, Department of Health and Human Services under contract with ABL.

The publication costs of this article were defrayed in part by payment of page charges. This article must therefore be hereby marked "advertisement" in accordance with 18 USC section 1734 solely to indicate this fact.

\section{References}

Adams, A., D. Gottschling, and C. Kaiser. 1995. Methods in yeast genetics. A laboratory course manual. Cold Spring Harbor Laboratory Press, Cold Spring Harbor, NY.

Akroyd, J., V.J. Fincham, A.R. Green, P. Levantis, S. Searle, and J.A. Wyke. 1987. Transcription of Rous sarcoma proviruses in rat cells is determined by chromosomal position effects that fluctuate and can operate over a long distance. Oncogene 1: 347-355.

Alani, E., L. Cao, and N. Kleckner. 1987. A method for gene disruption that allows repeated use of URA3 selection in the construction of multiply disrupted yeast strains. Genetics 116: 541-545.

Bailly, V., J. Lamb, P. Sung, S. Prakash, and L. Prakash. 1994. Specific complex formation between yeast RAD6 and RAD18 proteins: A potential mechanism for targeting RAD6 ubiquitin-conjugating activity to DNA damage sites. Genes \& Dev. 8: 811-820.

Bedell, M.A., N.A. Jenkins, and N.G. Copeland. 1996. Good genes in bad neighbourhoods. Nature Genet. 12: 229-232.

Boeke, J.D., D.J. Garfinkel, C.A. Styles, and G.R. Fink. 1985. Ty elements transpose through an RNA intermediate. Cell 40: 491-500.

Braunstein, M., A.B. Rose, S.G. Holmes, C.D. Allis, and J.R. Broach. 1993. Transcriptional silencing in yeast is associated with reduced nucleosome acetylation. Genes \& Dev. 7: 592604.

Braunstein, M., R.E. Sobel, C.D. Allis, B.M. Turner, and J.R. Broach. 1996. Efficient transcriptional silencing in Saccharomyces cerevisiae requires a heterochromatin histone acetylation pattern. Mol. Cell. Biol. 16: 4349-4356.

Cavalli, G., D. Bachmann, and F. Thoma. 1996. Inactivation of topoisomerases affects transcription-dependent chromatin transitions in rDNA but not in a gene transcribed by RNA polymerase II. $E M B O$ T. 15: 590-597.

Chalker, D.L. and S.B. Sandmeyer. 1992. Ty3 integrates within the region of RNA polymerase III transcription initiation. Genes \& Dev. 6: 117-128.

Christman, M.F., F.S. Dietrich, and G.R. Fink. 1988. Mitotic recombination in the rDNA of $S$. cerevisiae is suppressed by the combined action of DNA topoisomerases I and II. Cell 55: 413-425.

Christman, M.F., F.S. Dietrich, N.A. Levin, B.U. Sadoff, and G.R. Fink. 1993. The rRNA-encoding DNA array has an altered structure in topoisomerase I mutants of Saccharomyces cerevisiae. Proc. Nat1. Acad. Sci. 90: 7637-7641.

Clark-Adams, C.D., D. Norris, M.A. Osley, J.S. Fassler, and F. 
Winston. 1988. Changes in histone gene dosage alter transcription in yeast. Genes \& Dev. 2: 150-159.

Conklin, K.F. and M. Groudine. 1986. Varied interactions between proviruses and adjacent host chromatin. Mol. Cell. Biol. 6: 3999-4007.

Curcio, M.J. and D.J. Garfinkel. 1991a. Regulation of retrotransposition in Saccharomyces cerevisiae. Mol. Microbiol. 5: $1823-1829$.

- $1991 \mathrm{~b}$. Single-step selection for Tyl element retrotransposition. Proc. Nat1. Acad. Sci. 88: 936-940.

- 1992. Posttranslational control of Tyl retrotransposition occurs at the level of protein processing. Mol. Cell. Biol. 12: 2813-2825.

- 1994. Heterogeneous functional Tyl elements are abundant in the Saccharomyces cerevisiae genome. Genetics 136: $1245-1259$.

Curcio, M.J. and R.H. Morse. 1996. Tying together integration and chromatin. Trends Genet. 12: 436-438.

Curcio, M.J., A.M. Hedge, J.D. Boeke, and D.J. Garfinkel. 1990. Ty RNA levels determine the spectrum of retrotransposition events that activate gene expression in Saccharomyces cerevisiae. Mol. \& Gen. Genet. 220: 213-221.

Devine, S.E. and J.D. Boeke. 1996. Integration of the yeast retrotransposon Ty1 is targeted to regions upstream of genes transcribed by RNA polymerase III. Genes \& Dev. 10: 620633.

Dillin, A. and J. Rine. 1995. On the origin of a silencer. Trends Biochem. Sci. 20: 231-235.

Dohmen, R.J., K. Madura, B. Bartel, and A. Varshavsky. 1991. The N-end rule is mediated by the UBC2 (RAD6) ubiquitinconjugating enzyme. Proc. Nat1. Acad. Sci. 88: 7351-7355.

Elder, R.T., T.P. St. John, D.T. Stinchcomb, and R.W. Davis. 1981. Studies on the transposable element Tyl of yeast. I. RNA homologous to Tyl. Cold Spring Harbor Symp. Quant. Biol. 45: 581-584.

Farabaugh, P.J. 1995. Post-transcriptional regulation of transposition by Ty retrotransposons of Saccharomyces cerevisiae. J. Biol. Chem. 270: 10361-10364.

Feinstein, S.C., S.R. Ross, and K.R. Yamamoto. 1982. Chromosomal position effects determine transcriptional potential of integrated mammary tumor virus DNA. I. Mol. Biol. 156: $549-566$.

Garfinkel, D.J., M.F. Mastrangelo, N.J. Sanders, B.K. Shafer, and J.N. Strathern. 1988. Transposon tagging using Ty elements in yeast. Genetics 120: 95-108.

Gerring, S.L., C. Connelly, and P. Hieter. 1991. Positional mapping of genes by chromosome blotting and chromosome fragmentation. In Guide to yeast genetics and molecular biology (ed. C. Guthrie and G.R. Fink), pp. 57-76. Academic Press, San Diego, CA.

Gietz, D., A. St. Jean, R.A. Woods, and R.H. Schiestl. 1992. Improved method for high efficiency transformation of intact yeast cells. Nucleic Acids Res. 20: 1425.

Gottlieb, S. and R.E. Esposito. 1989. A new role for a yeast transcriptional silencer gene, SIR2, in regulation of recombination in ribosomal DNA. Cell 56: 771-776.

Gottschling, D.E. 1992. Telomere-proximal DNA in Saccharomyces cerevisiae is refractory to methyltransferase activity in vivo. Proc. Nat1. Acad. Sci. 89: 4062-4065.

Han, M. and M. Grunstein. 1988. Nucleosome loss activates yeast downstream promoters in vivo. Cell 55: 1137-1145.

Han, M., M. Chang, U.J. Kim, and M. Grunstein. 1987. Histone $\mathrm{H} 2 \mathrm{~B}$ repression causes cell-cycle-specific arrest in yeast: Effects on chromosomal segregation, replication, and transcription. Cell 48: 589-597.

Hirschhorn, J.N., S.A. Brown, C.D. Clark, and F. Winston. 1992.
Evidence that SNF2/SWI2 and SNF5 activate transcription in yeast by altering chromatin structure. Genes \& Dev. 6: $2288-2298$.

Jentsch, S., J.P. McGrath, and A. Varshavsky. 1987. The yeast DNA repair gene $R A D 6$ encodes a ubiquitin-conjugating enzyme. Nature 329: 131-134.

Ji, H., D.P. Moore, M.A. Blomberg, L.T. Braiterman, D.F. Voytas, G. Natsoulis, and J.D. Boeke. 1993. Hotspots for unselected Ty1 transposition events on yeast chromosome III are near tRNA genes and LTR sequences. Cell 73: 1007-1018.

Kang, X.L., F. Yadao, R.D. Gietz, and B.A. Kunz. 1992. Elimination of the yeast $R A D 6$ ubiquitin conjugase enhances base-pair transitions and G.C $\rightarrow$ T.A transversions as well as transposition of the Ty element: Implications for the control of spontaneous mutation. Genetics 130: 285-294.

Klar, A.J.S., S. Fogel, and K. MacLeod. 1979. MAR1-A regulator

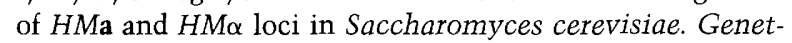
ics 93: 37-50.

Laurenson, P. and J. Rine. 1992. Silencers, silencing, and heritable transcriptional states. Microbiol. Rev. 56: 543-560.

Lawrence, C. 1994. The RAD6 DNA repair pathway in Saccharomyces cerevisiae: What does it do, and how does it do it? BioEssays 16: 253-258.

Lea, D.E. and C.A. Coulson. 1949. The distribution of the numbers of mutants in bacterial populations. I. Genet. 49: 264285.

Lee, D.Y., J.J. Hayes, D. Pruss, and A.P. Wolffe. 1993. A positive role for histone acetylation in transcription factor access to nucleosomal DNA. Cell 72: 73-84.

Liebman, S.W. and G. Newnam. 1993. A ubiquitin-conjugating enzyme, $R A D 6$, affects the distribution of Ty1 retrotransposon integration positions. Genetics 133: 499-508.

Lohe, A.R. and A.J. Hilliker. 1995. Return of the H-word (heterochromatin|. Curr. Opin. Genet. Dev. 5: 746-755.

Loo, S. and J. Rine. 1994. Silencers and domains of generalized repression. Science 264: 1768-1771.

Madura, K., R.J. Dohmen, and A. Varshavsky. 1993. N-recognin/Ubc2 interactions in the N-end rule pathway. J. Biol. Chem. 268: 12046-12054.

Moazed, D. and A.D. Johnson. 1996. A deubiquitinating enzyme interacts with SIR4 and regulates silencing in S. cerevisiae. Cell 86: 667-677.

Moore, G.D., D.A. Sinclair, and T.A. Grigliatti. 1983. Histone gene multiplicity and position effect variegation in Drosophila melanogaster. Genetics 105: 327-344.

Morrison, A., E.J. Miller, and L. Prakash. 1988. Domain structure and functional analysis of the carboxyl-terminal polyacidic sequence of the RAD6 protein of Saccharomyces cerevisiae. Mol. Cell. Biol. 8: 1179-1185.

Natsoulis, G., W. Thomas, M.C. Roghmann, F. Winston, and J.D. Boeke. 1989. Tyl transposition in Saccharomyces cerevisiae is nonrandom. Genetics 123: 269-279.

Norris, D. and M.A. Osley. 1987. The two gene pairs encoding $\mathrm{H} 2 \mathrm{~A}$ and $\mathrm{H} 2 \mathrm{~B}$ play different roles in the Saccharomyces cerevisiae life cycle. Mol. Cell. Biol. 7: 3473-3481.

Norris, D., B. Dunn, and M.A. Osley. 1988. The effect of histone gene deletions on chromatin structure in Saccharomyces cerevisiae. Science 242: 759-761.

Olson, M.V. 1991. Genome structure and organization in Saccharomyces cerevisiae. In The molecular and cellular biology of the yeast Saccharomyces (ed. J.R. Broach, J.R. Pringle, and E.W. Jones), pp. 1-40. Cold Spring Harbor Laboratory Press, Cold Spring Harbor, NY.

Oyen, T.B. and O.S. Gabrielsen. 1983. Non-random distribution of the Tyl elements within nuclear DNA of Saccharomyces cerevisiae. FEBS Lett. 161: 201-206. 
Paetkau, D.W., J.A. Riese, W.S. MacMorran, R.A. Woods, and R.D. Gietz. 1994. Interaction of the yeast RAD7 and SIR3 proteins: Implications for DNA repair and chromatin structure. Genes \& Dev. 8: 2035-2045.

Park, E.C. and J.W. Szostak. 1990. Point mutations in the yeast histone $\mathrm{H} 4$ gene prevent silencing of the silent mating type locus HML. Mol. Cell. Biol. 10: 4932-4934.

Petes, T.D. 1980 . Unequal meiotic recombination within tandem arrays of yeast ribosomal DNA genes. Cell 19: 765-774.

Picologlou, S., N. Brown, and S.W. Liebman. 1990. Mutations in $R A D 6$, a yeast gene encoding a ubiquitin-conjugating enzyme, stimulate retrotransposition. Mol. Cell. Biol. 10: $1017-1022$.

Piper, P.W., A. Lockheart, and N. Patel. 1984. A minor class of $5 S$ rRNA genes in Saccharomyces cerevisiae X2180-1B, one member of which lies adjacent to a Ty transposable element. Nucleic Acids Res, 12: 4083-4096.

Prakash, S., P. Sung, and L. Prakash. 1993. DNA repair genes and proteins of Saccharomyces cerevisiae. Annu. Rev. Genet. 27: 33-70.

Renauld, H., O.M. Aparicio, P.D. Zierath, B.L. Billington, S.K. Chhablani, and D.E. Gottschling. 1993. Silent domains are assembled continuously from the telomere and are defined by promoter distance and strength, and by SIR3 dosage. Genes \& Dev. 7: 1133-1145.

Rivier, D.H. and L. Pillus. 1994. Silencing speaks up. Cell 76: $963-966$.

Roest, H.P., J. van Klaveren, J. de Wit, C.G. van Gurp, M.H.M. Koken, M. Vermey, J.H. van Roijen, J.W. Hoogerbrugge, J.T.M. Vreeburg, W.M. Baarends, D. Bootsma, J.A. Grootegoed, and J.H.J. Hoeijmakers. 1996. Inactivation of the HR6B ubiquitin-conjugating DNA repair enzyme in mice causes male sterility associated with chromatin modification. Cell 86: 799-810.

Rustchenko, E.P. and F. Sherman. 1994. Physical constitution of ribosomal genes in common strains of Saccharomyces cerevisiae. Yeast 10: 1157-1171.

Schmitt, M.E., T.A. Brown, and B.L. Trumpower. 1990. A rapid and simple method for preparation of RNA from Saccharomyces cerevisiae. Nucleic Acids Res. 18: 3091-3092.

Shore, D. 1994. RAP1: A protean regulator in yeast. Trends Genet. 10: 408-412.

Shore, D., M. Squire, and K.A. Nasmyth. 1984. Characterization of two genes required for the position-effect control of yeast mating-type genes. EMBO J. 3: 2817-2823.

Singh, J. and A.J. Klar. 1992. Active genes in budding yeast display enhanced in vivo accessibility to foreign DNA methylases: a novel in vivo probe for chromatin structure of yeast. Genes \& Dev. 6: 186-196.

Smith, J.S. and J.D. Boeke. 1997. An unusual form of transcriptional silencing in the yeast ribosomal DNA. Genes \& Dev. (this issue).

Sung, P., S. Prakash, and L. Prakash. 1988. The RAD6 protein of Saccharomyces cerevisiae polyubiquitinates histones, and its acidic domain mediates this activity. Genes \& Dev. 2: 1476-1485.

Swerdlow, P.S., T. Schuster, and D. Finley. 1990. A conserved sequence in histone $\mathrm{H} 2 \mathrm{~A}$ which is a ubiquitination site in higher eucaryotes is not required for growth in Saccharomyces cerevisiae. Mol. Cell. Biol. 10: 4905-4911.

Szauter, P. 1984. An analysis of regional constraints on exchange in Drosophila melanogaster using recombination-defective meiotic mutants. Genetics 106: 45-71.

Szostak, J.W. and R. Wu. 1980. Unequal crossing over in the ribosomal DNA of Saccharomyces cerevisiae. Nature 284: 426-430.
Thompson, J.S., X. Ling, and M. Grunstein. 1994. Histone H3 amino terminus is required for telomeric and silent mating locus repression in yeast. Nature 369: 245-247.

Thon, G., A. Cohen, and A.J. Klar. 1994. Three additional linkage groups that repress transcription and meiotic recombination in the mating-type region of Schizosaccharomyces pombe. Genetics 138: 29-38.

Vincent, A. and T.D. Petes. 1986. Isolation and characterization of a Ty element inserted into the ribosomal DNA of the yeast Saccharomyces cerevisiae. Nucleic Acids Res. 14: 2939-2949.

Watkins, J.F., P. Sung, S. Prakash, and L. Prakash. 1993. The extremely conserved amino terminus of RAD6 ubiquitinconjugating enzyme is essential for amino-end rule-dependent protein degradation. Genes \& Dev. 7: 250-261.

Weiler, K.S. and B.T. Wakimoto. 1995. Heterochromatin and gene expression in Drosophila. Annu. Rev. Genet. 29: 577605.

Winston, F., F. Chumley, and G.R. Fink. 1983. Eviction and transplacement of mutant genes in yeast. Methods Enzymol. 101: 211-228.

Wright, J.H., D.E. Gottschling, and V.A. Zakian. 1992. Saccharomyces telomeres assume a non-nucleosomal chromatin structure. Genes \& Dev. 6: 197-210. 


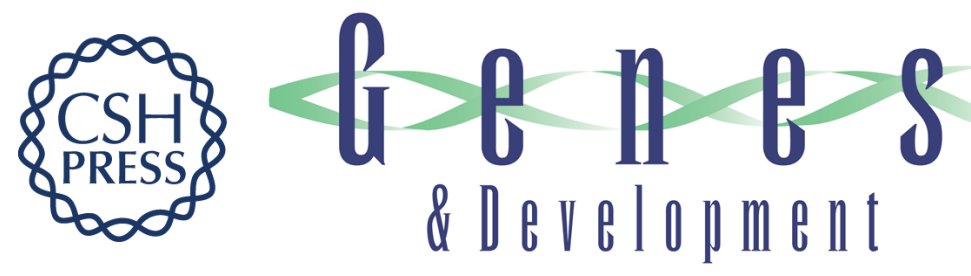

\section{Transcriptional silencing of Ty1 elements in the RDN1 locus of yeast.}

M Bryk, M Banerjee, M Murphy, et al.

Genes Dev. 1997, 11:

Access the most recent version at doi:10.1101/gad.11.2.255 $\begin{array}{ll}\text { References } & \begin{array}{l}\text { This article cites } 76 \text { articles, } 39 \text { of which can be accessed free at: } \\ \text { http://genesdev.cshlp.org/content/11/2/255.full.html\#ref-list-1 }\end{array}\end{array}$

License

Email Alerting

Receive free email alerts when new articles cite this article - sign up in the box at the top Service right corner of the article or click here.

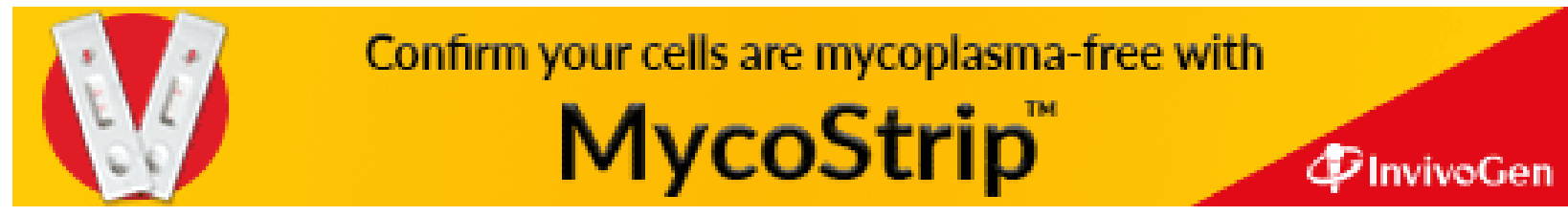

